\begin{tabular}{|c|c|}
\hline Title & Effect evaluation of freeze thaw on resilient modulus of unsaturated granular base course material in pavement \\
\hline Author(s) & Ishikawa, Tatsuya; Lin, Tianshu; Kawabata, Shinichiro; Kamey ama, Shuichi; Tokoro, Tetsuya \\
\hline Citation & $\begin{array}{l}\text { Transportation geotechnics, 21, } 100284 \\
\text { https://doi.org/10.1016/.trgeo.2019.100284 }\end{array}$ \\
\hline Issue Date & $2019-12$ \\
\hline Doc URL & http:/hdl.handle.net/2115/83366 \\
\hline Rights & $\begin{array}{l}\text { (1) < 2ulys. Inis manuscript version is made avallable under the CC-BY-IVC-NV } 4.0 \text { license } \\
\text { http://creativecommons.org/icenses/by-nc-nd/4.0/ }\end{array}$ \\
\hline Rights(URL) & http://creativecommons.org/icenses/by-nc-nd/4.0/ \\
\hline Type & article (author version) \\
\hline File Information & TG17-10.pdf \\
\hline
\end{tabular}

Instructions for use 


\section{Effect Evaluation of Freeze-Thaw on Resilient Modulus of Unsaturated Granular Base Course Material in Pavement}

Tatsuya ISHIKAWA, Professor, Dr.Eng.

Faculty of Engineering, Hokkaido University

Kita 13, Nishi 8, Kita-Ku, Sapporo 060-8628, Japan

Tel: +81-11-706-6202, Fax: +81-11-706-6202

E-mail: t-ishika@eng.hokudai.ac.jp

Tianshu LIN, PhD Student, Mr.Eng.

Graduate School of Engineering, Hokkaido University

Kita 13, Nishi 8, Kita-Ku, Sapporo 060-8628, Japan

Tel: +81-11-706-6203, Fax: +81-11-706-6203

E-mail: ts_lin@eis.hokudai.ac.jp

Shinichiro KAWABATA, Professor, Dr.Eng.

Faculty of Engineering, Hokkaido University of Science

4-1, Maeda 7-jo 15-chome, Teine-ku, Sapporo 006-8585, Japan

Tel: $+81-11-688-2268$

E-mail:kawabata@hus.ac.jp

Shuichi KAMEYAMA, Professor, Dr.Eng.

Faculty of Engineering, Hokkaido University of Science

4-1, Maeda 7-jo 15-chome, Teine-ku, Sapporo 006-8585, Japan

Tel: +81-11-688-2264

E-mail: kameyama@hus.ac.jp

Tetsuya TOKORO, Associate Professor, Dr.Eng.

Faculty of Engineering, Hokkai-Gakuen University

1-1, Minami 26 Nishi 11, Chuo-ku, Sapporo 064-0926, Japan

Tel: +81-11-841-1161

E-mail: tokoro@cvl.hokkai-s-u.ac.jp 


\title{
Effect Evaluation of Freeze-Thaw on Resilient Modulus of Unsaturated Granular Base Course Material in Pavement
}

\author{
Tatsuya ISHIKAWA*, Tianshu LIN ${ }^{* *}$, Shinichiro KAWABATA ${ }^{* * *}$, Shuichi KAMEYAMA ${ }^{* * *}$ and \\ Tetsuya TOKORO*** \\ * Faculty of Engineering, Hokkaido University \\ ** Graduate School of Engineering, Hokkaido University \\ ${ }^{* * *}$ Faculty of Engineering, Hokkaido University of Science \\ ${ }^{* * * * *}$ Faculty of Engineering, Hokkai-Gakuen University
}

\begin{abstract}
This study examines the effects of freeze-thaw and water content on the resilient deformation characteristics of subbase course materials to evaluate the mechanical behavior of granular base in cold regions. A series of resilient modulus tests on subbase course materials under various water contents were conducted using a newly developed test apparatus. Besides, the test results were compared with the results of freeze-thaw CBR tests and the long-term field measurement at a model pavement structure including FWD tests. As the results, it was revealed that the resilient deformation characteristics of unbound granular base materials (UGBMs) deteriorate due to freeze-thaw and increment of the water content in thawing season. This indicates that the freeze-thaw of granular base has a strong influence on the fatigue life of pavement structures.
\end{abstract}

Keywords: base course; resilient deformation characteristics; unsaturated soil; freeze-thaw action; laboratory element test 


\section{INTRODUCTION}

In snowy cold regions such as Hokkaido, a northern island in Japan, the $0{ }^{\circ} \mathrm{C}$ isotherm may penetrate deep into the pavement, thereby causing frost heave and swelling of pavement surface, or cracking in asphalt-mixture layer (hereafter referred to as the "As layer") during the freezing period of winter. In addition, the water content rises as a result of the inflow of snowmelt water or the thawing of ice lenses, which causes a temporary decrease in the strength of subgrade and base course during the thawing season (e.g. Jong et al. 1998, Simonsen and Icacsson 1999, Abe et al. 2009, Kootstra et al. 2010). Such phenomena specific to cold regions are thought to accelerate the deterioration of pavement structures and loss of functionality (Kubo, 1979, Zaman et al. 1999). Recently, a new theoretical design method (JRA 2006) has come into use to predict the long-term performance of transportation infrastructure for the rationalization of the design procedure, and contribute to the structural design of asphalt pavements in cold regions. This theoretical approach can take the above-mentioned climate-related degradation of pavement structures into consideration. However, there have been little researches like Simonsen et al. (2002), Bozyurt et al. (2013), and Edil and Cetin (2015), which elucidate the frost-heave phenomenon of pavement during the freezing period and the temporary deterioration of the bearing capacity of base course and subgrade during the thawing period, and model the mechanical behavior. To develop a mathematical model of the mechanical response of the subbase course in cold regions and incorporate it into the theoretical design method for pavement structures in the future, a detailed understanding of the mechanical behavior of the subgrade and base course during freeze-thaw is essentially required. Especially, it is necessary to quantitatively evaluate the deformation-strength characteristics and infiltration characteristics (water-retentivity property and permeability) of unbound granular base course materials subjected to cyclic freeze-thaw actions under various compaction conditions and water contents, by performing laboratory element tests with high-precision under sufficiently controlled experimental conditions.

In the Japanese Handbook of Pavement Investigation and Examination Methods (JRA 2007), the "Method of Test for Modified California Bearing Ratio (E001)" and "Method of Test for Resilient Modulus of Unbound Granular Base Material and Subgrade Soils (E016)" are specified as testing methods for the subbase course materials when conducting the design calculations for the pavement structure. However, in general, these tests are designed to examine the deformation-strength characteristics of subbase course materials with the optimum water content, and not to evaluate in detail the effects of freeze-thaw action or the water content on the material properties. Therefore, in previous studies (Ishikawa et al. 2012, 2014), we developed a freeze-thaw California Bearing Ratio (CBR) test apparatus and a medium-sized triaxial apparatus for unsaturated soils, to examine the effects of freeze-thaw and water content on the bearing capacity and deformation characteristics of granular subbase course material. Furthermore, a structural analysis of the pavement was also conducted using the multi-layer elastic analysis, considering the performance changes in the granular base during the freeze-thaw cycle (Ishikawa and Kawabata 2016). As the results, it was revealed that the freeze-thaw and the seasonal changes in water content had a considerable effect on the reduction of the fatigue life of the pavement structure in cold regions. However, the synergistic effects of water content and freeze-thaw on the resilient modulus $\left(M_{r}\right)$, which is associated with the elastic modulus $(E)$ used in the design calculation for pavement structures applying the multi-layer elastic theory or finite element method, have not yet been quantitatively evaluated and modeled.

This study examines the effects of freeze-thaw and water content on the deformation-strength characteristics of subbase course material to evaluate the change in mechanical behavior of granular base caused by freeze-thaw and concurrent seasonal fluctuations in water content, and the influences on the fatigue life of pavement structures. For this reason, in this study, CBR tests of freeze-thawed subbase course materials under various water contents, and the suction-controlled resilient modulus (MR) tests in unsaturated condition were carried out. By comparing results of the above-mentioned laboratory element tests with those of long-term field measurement including Falling Weight Deflection (FWD) tests, we discuss the relevance of the resilient modulus $\left(M_{r}\right)$ to the CBR values and the elastic modulus $(E)$ obtained from FWD tests to quantitatively evaluate the effects on the 
changes in the performance of subbase course material. Finally, we attempt to develop a simple mathematical model of the mechanical response of subbase course materials subjected to freeze-thaw action and seasonal fluctuations in water content, in order to establish a method for evaluating the long-term performance of the granular base at pavement structures in cold regions.

\section{TESTING METHODS}

\section{Resilient Modulus Tests on Unsaturated Subbase Course Materials}

\section{Medium-size Triaxial Apparatus for Unsaturated Soils}

A schematic diagram of a suction-controlled medium-size triaxial apparatus for unsaturated soils is shown in Figure 1. One key feature of the apparatus is the structural design of the cap and pedestal as shown in Figure 2. Here, the versapor membrane filter is a kind of microporous membrane filters made from hydrophilic acrylic copolymer, and polyflon filter is a hydrophobic filter made from polytetrafluoroethylene. Accordingly, the apparatus adopts the pressure membrane method. The other key features are as follows:

- Since the specifications of a medium-size cylindrical specimen were $\mathrm{H}=300 \mathrm{~mm}$ in height and $\mathrm{D}=150 \mathrm{~mm}$ in diameter $(\mathrm{H} / \mathrm{D}=2.00)$, it was possible to conduct resilient modulus tests on subbase course materials compliant to the "Handbook of Pavement Investigation and Examination Methods" (JRA 2007) and the "Standard Method of Test for Determining the Resilient Modulus of Soils and Aggregate Materials (AASHTO Designation: T307-99)" (AASHTO 2003).

- The apparatus can apply the matric suction from both ends of the specimen (Figure 1). Besides, pore water is allowed to drain from both cap and pedestal. Accordingly, the apparatus can reduce the testing time by shortening the length of drainage path to half of the specimen height, in addition to the effect of versapor membrane filter.

- The apparatus can apply axial load to a specimen with high accuracy by both strain-controlled method and stress-controlled method with a hybrid actuator. Moreover, the apparatus can perform both monotonic loading tests with very slow loading rate, and cyclic loading tests in which the maximum frequency of cyclic loading is up to about $10 \mathrm{~Hz}$

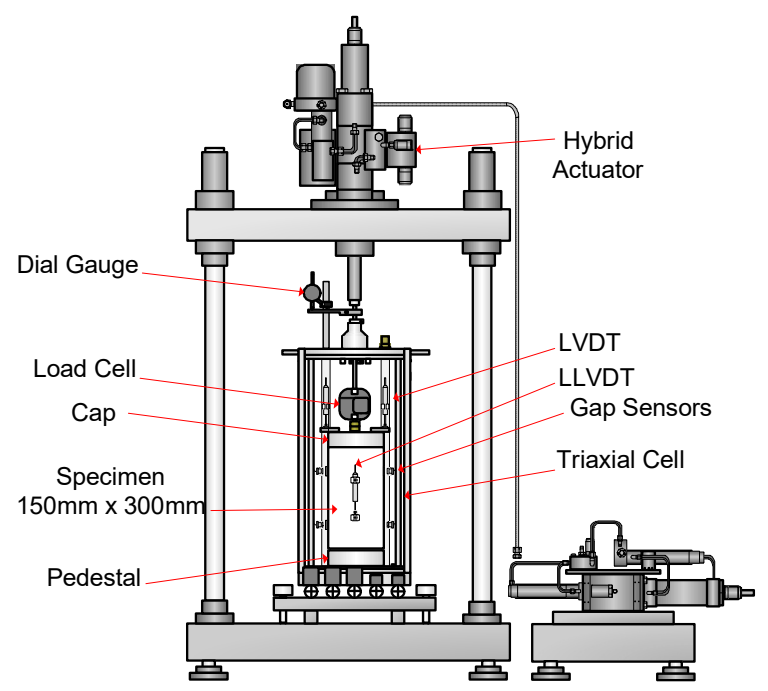

(a) Schematic diagram of test apparatus.

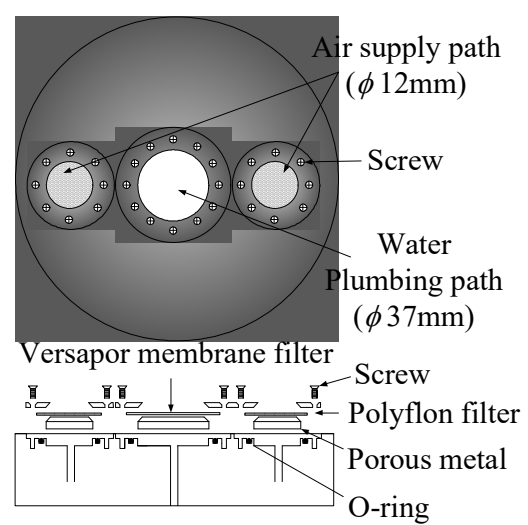

(b) Structural design of cap and pedestal.

Figure 1. Medium-size triaxial apparatus for unsaturated soils.

Details about the test apparatus were provided in the previous study (Ishikawa et al. 2014). Measurements of axial strain $\left(\varepsilon_{a}\right)$ along the specimen axis were taken using two linear voltage 
differential transformers (LVDTs) installed on top of the inner cap of triaxial cell and one displacement transducer (EXT) installed externally. It has been reported that the influence of bedding error (BE) is prominent in triaxial compression tests on hard geomaterials like gravel (Tatsuoka and Shibuya 1992). To eliminate such measurement errors, we corrected the axial strain measured by the LVDTs by referring to the previous study (Ishikawa et al. 2014). On the other hand, volumetric strain $\left(\varepsilon_{v}\right)$ was mainly calculated by using a calculation method proposed by Kato and Kawai (2000) based on the lateral displacements of the specimen, which were measured by a total of four proximity transducers (gap sensors, GSs): each GS was installed at the points of $1 / 4$ or 3/4 of the specimen height diagonally opposite to each other around the specimen diameter.

\section{Preparation of Test Specimens}

As a test sample, we used natural crusher-run (C-40) made from angular, crush, hard andesite, which is commonly employed at the subbase course of pavement structures in Japan. The grain size distribution curve and physical properties of C-40 are shown in Figure 2 and Table 1, respectively. The degree of compaction $\left(D_{\mathrm{c}}\right)$ for the specimen was basically set to $95 \%$. To unify the compaction energy, an air-dried sample (water content, $w=1.2 \%$ ) was injected into the mold with the attached membrane in five different layers, and each layer was compacted by vibration for a certain period using a vibrator. To avoid functional damages of microporous membrane filters installed in the pore water pressure control channels as a result of direct contact with the coarse-grained particles, we inserted a filter paper between the end surfaces of the specimen and the cap/pedestal, and spread fine particles with grain size of $2 \mathrm{~mm}$ or smaller over both ends of the specimen. It is noted that the overall grain size distribution for the specimen did not change. After tests under unsaturated conditions, we checked an air entry value (AEV) of microporous membrane filter and confirmed that there was no damage to the filter during the test.

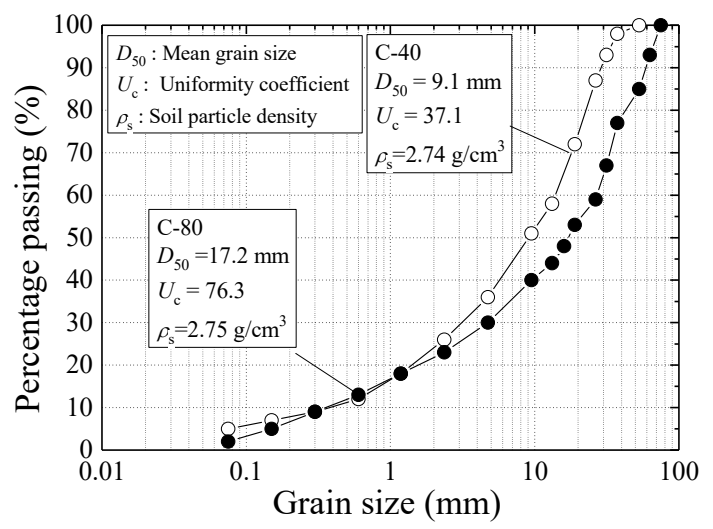

Figure 2. Grain size distribution and physical properties of subbase course material.

Table 1. Physical properties of base course materials.

\begin{tabular}{ccccccccc}
\hline \multirow{2}{*}{ Name } & $\rho_{\mathrm{dmax}}$ & $W_{\mathrm{opt}}$ & $F_{\mathrm{c}}$ & $P I$ & Soundness & $\begin{array}{c}\text { Water } \\
\text { absorption }\end{array}$ & $\begin{array}{c}\text { Abrasion } \\
\text { loss }\end{array}$ & $C B R$ \\
\cline { 2 - 9 } & $\mathrm{g} / \mathrm{cm}^{3}$ & $\%$ & $\%$ & & $\%$ & $\%$ & $\%$ & $\%$ \\
\hline $\mathrm{C}-40$ & 2.070 & 8.2 & 5.20 & $\mathrm{NP}$ & 4.6 & 3.80 & 24.6 & 85.8 \\
\hline $\mathrm{C}-80$ & 2.124 & 6.8 & 3.08 & $\mathrm{NP}$ & 0.8 & 1.86 & 18.8 & 85.6 \\
\hline
\end{tabular}

After setting a specimen, water content adjustment and consolidation were conducted to prepare a test under air-dried, unsaturated, or saturated conditions. An air-dried specimen (degree of saturation, $S_{r}=8.2 \%$ ) was prepared through isotropic consolidation with the specified effective confining pressure $\left(\sigma_{c}^{\prime}\right)$ of $49 \mathrm{kPa}$. A saturated specimen $\left(S_{r}=100 \%\right)$ was prepared by supplying $\mathrm{CO}_{2}$ and de-aired water to the air-dried specimen for a specified period, saturating with a back pressure of $200 \mathrm{kPa}$, and then isotropically consolidating at $\sigma^{\prime}{ }_{c}=49 \mathrm{kPa}$ until the B-coefficient of 
pore water pressure was 0.96 or higher. An unsaturated specimen $\left(S_{r}=36.7 \%\right)$ was prepared by isotropically consolidating a specimen under capillary saturation condition at the net normal stress $\left(\sigma_{\text {net }}\right)$ of $49 \mathrm{kPa}\left(\sigma_{\text {net }}=\sigma_{c}-u_{a}\right.$, here, confining pressure $\sigma_{c}=249 \mathrm{kPa}$, pore air pressure $u_{a}$, and pore water pressure $u_{w}=200 \mathrm{kPa}$ ), and then reducing the pore water pressure to apply the prescribed matric suction $(s)\left(s=u_{a}-u_{w}\right)$ of $10 \mathrm{kPa}$ to the specimen for the drying path. It is noted that the degree of saturation for the unsaturated specimen was set up in consideration of the water content for the subbase course of the actual pavement structure during regular season except the freezing period or thawing period as will be described in a later section, and the matric suction was determined based on the soil water characteristic curve (SWCC) for C-40. Figure 3 shows the SWCC under different degree of compaction $\left(D_{\mathrm{c}}\right)$ and freeze-thaw history, together with the fitting curves by LG-A model (Mori et al. 2009) and the residual degree of saturation $\left(S_{r r}\right)$. According to Figure 3, though the water retentivity increases with the increase in the degree of compaction, the influence of freeze-thaw can hardly be recognized for non-frost susceptible C-40. On the other hand, Zhang et al. (2014) is referred for detailed information about the strength characteristics of unsaturated C-40 in the monotonic triaxial compression tests.

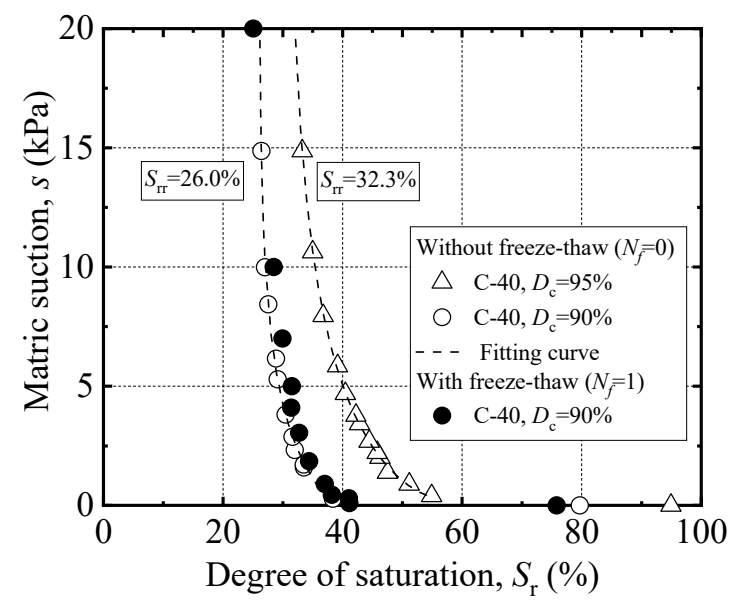

Figure 3. Soil-water characteristic curves of C-40 (after Aoyagi et al. 2019).

\section{Resilient Modulus Test (MR Test)}

After preparing the specimen, a resilient modulus test was conducted under fully drained condition, with a constant effective confining pressure or net normal stress pursuant to the AASHTO Designation: T307-99. Here, the loading waveform of the deviator stress $(q)$, which was expressed as the sum of contact stress $\left(q_{\text {cont }}\right)$ and cyclic stress $\left(q_{\text {cyclic }}\right)$, was set as a haversine wave with a load duration of $0.1 \mathrm{sec}$ followed by a rest period of $0.9 \mathrm{sec}$. Cyclic loading in a MR test consists of a conditioning process (number of loading cycles: $N_{c}=1000$ cycles), which eliminates the initial irregularities on the top or bottom end surfaces of the specimen such as the bedding error, and an actual testing process $\left(N_{c}=100\right.$ cycles for each loading stage), which contains 15 successive loading stages with varying combinations of confining pressure and deviator stress as shown in Table 2. In this case, resilient modulus $\left(M_{r}\right)$ was defined as the average ratio of the amplitude of the repeated axial stress $\left(q_{\text {cyclic }}\right)$ to the amplitude of the resultant recoverable axial strain $\left(\varepsilon_{r}\right)$ generated in one cycle for the last five cycles of each loading stage. It is noted that the E016 differs from this study or AASHOTO T307-99 in that it adopts undrained condition during cyclic loading because it uses a test apparatus without drain channels, though the loading patterns are similar. 
Table 2. Loading conditions of MR tests

\begin{tabular}{lccccc}
\hline \multirow{2}{*}{ Name } & $\sigma_{\mathrm{c}}^{\prime}$ & $q_{\text {cont }}$ & $q_{\text {cyclic }}$ & $q_{\max }$ & $N_{\mathrm{c}}$ \\
\cline { 2 - 6 } & $\mathrm{kPa}$ & $\mathrm{kPa}$ & $\mathrm{kPa}$ & $\mathrm{kPa}$ & $\mathrm{cycle}$ \\
\hline Conditioning process & 103.4 & 10.3 & 93.1 & 103.4 & 1000 \\
\hline Testing process MR-1 & 20.7 & 2.1 & 18.6 & 20.7 & 100 \\
\hline Testing process MR-2 & 20.7 & 4.1 & 37.3 & 41.4 & 100 \\
\hline Testing process MR-3 & 20.7 & 6.2 & 55.9 & 62.1 & 100 \\
\hline Testing process MR-4 & 34.5 & 3.5 & 31.0 & 34.5 & 100 \\
\hline Testing process MR-5 & 34.5 & 6.9 & 62.0 & 68.9 & 100 \\
\hline Testing process MR-6 & 34.5 & 10.3 & 93.1 & 103.4 & 100 \\
\hline Testing process MR-7 & 68.9 & 6.9 & 62.0 & 68.9 & 100 \\
\hline Testing process MR-8 & 68.9 & 13.8 & 124.1 & 137.9 & 100 \\
\hline Testing process MR-9 & 68.9 & 20.7 & 186.1 & 206.8 & 100 \\
\hline Testing process MR-10 & 103.4 & 6.9 & 62.0 & 68.9 & 100 \\
\hline Testing process MR-11 & 103.4 & 10.3 & 93.1 & 103.4 & 100 \\
\hline Testing process MR-12 & 103.4 & 20.7 & 186.1 & 206.8 & 100 \\
\hline Testing process MR-13 & 137.9 & 10.3 & 93.1 & 103.4 & 100 \\
\hline Testing process MR-14 & 137.9 & 13.8 & 124.1 & 137.9 & 100 \\
\hline Testing process MR-15 & 137.9 & 27.6 & 248.2 & 275.8 & 100 \\
\hline
\end{tabular}

\section{Freeze-Thaw CBR Test on Unsaturated Subbase Course Materials}

\section{CBR Test Apparatus for Freeze-thawed Soils}

A schematic diagram of a freeze-thawing CBR (California Bearing Ratio) test apparatus is shown in Figure 4. This test apparatus is based on a general CBR test apparatus that has been improved to reproduce in a laboratory environment the freeze-thaw history expected to be applied to the base course materials in the in-situ pavement structures. It has the following features:

- The apparatus, which allows free water absorption or drainage (open-system freezing) or suppresses it (closed-system freezing) during the freeze-thaw process, can perform a frost-heave test compliant with "Test Method for Frost Heave Prediction of Soils (JGS 0172-2003)" (JGS 2003) on a CBR test specimen ( $\phi=150 \mathrm{~mm}, H=125 \mathrm{~mm}$ ).

- Since the temperatures of both ends of the specimen are controlled independently, the apparatus can subject a CBR test specimen to a desired one-dimensional freeze-thaw history at a constant freezing rate (moving speed of frost line).

- Since the apparatus can conduct a CBR test immediately after the freeze-thaw process without moving the sample, the effects of the freeze-thaw action on the bearing-capacity characteristics of unbound granular base materials can be examined under clear boundary condition, as well as the initial conditions. 

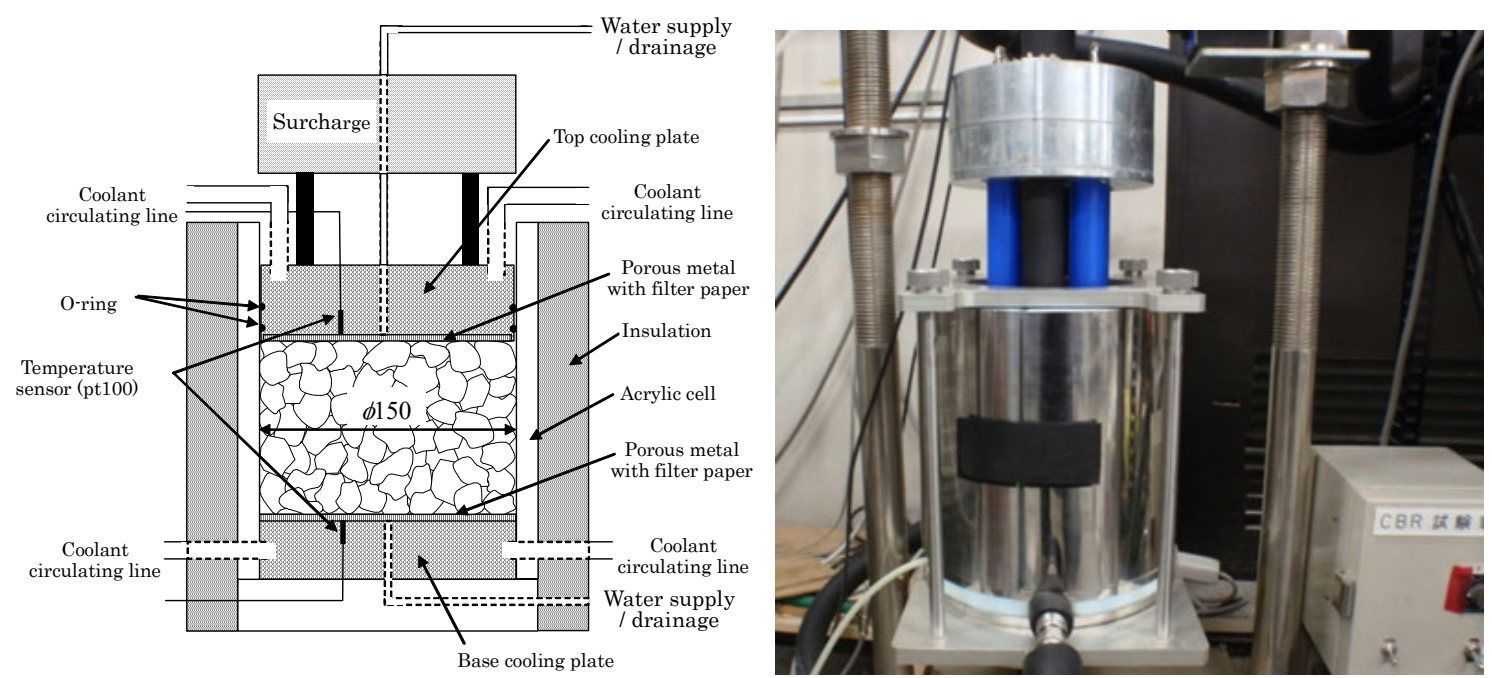

Figure 4. Freeze-thawing CBR test apparatus.

\section{Freeze-thaw CBR Test}

A series of freeze-thaw CBR tests was conducted under three different water contents along with three different patterns of freeze-thaw history in order to examine the effects of freeze-thaw action and water content on the frost-heave and bearing-capacity characteristics of subbase course material. To compare the results of CBR tests with those of MR tests mentioned above, the natural crusher-run (C-40) was used as the test sample. The specimen was prepared by compacting the air-dried samples with a vibrator at a degree of compaction $\left(D_{\mathrm{c}}\right)$ of $95 \%$ ("air-dried condition", $S_{r}=12.3 \%$ ). Then, air-dried specimens were saturated with permeating water for 1 hour ("saturation condition", $S_{r}=$ $95.0 \%$ ), and after the saturation process saturated specimens were allowed to drain by gravity for 3 hours ("wet condition", $S_{r}=67.0 \%$ ). Therefore, there were three types of specimens defined by the difference in initial water content. A freeze-thaw CBR test of C-40 was conducted as follows. According to JGS 0172-2003, freeze-thaw of the specimen was performed with closed-system freezing so that the initial water content of the specimen could be maintained. In the freeze-thaw process, after applying a thermal shock via the lower end of the specimen, the temperature of the top cooling plate was fixed at $0{ }^{\circ} \mathrm{C}$, while the temperature of the base cooling plate was lowered from $0{ }^{\circ} \mathrm{C}$ at the cooling rate of $-0.15{ }^{\circ} \mathrm{C} / \mathrm{h}$ until the freezing line passes the upper end of the specimen. Subsequently, the specimen was thawed by keeping the temperatures of both cooling plates at $10{ }^{\circ} \mathrm{C}$ for 24 hours. The above-mentioned series of operations was defined as one freeze-thaw process cycle. The freeze-thaw process was repeated, and the number of freeze-thaw process cycles $\left(N_{\mathrm{f}}\right)$ was given in three patterns of $N_{\mathrm{f}}=0$ (no freezing), 1, 2, and 5 cycles. After subjection to the freeze-thaw history $\left(N_{\mathrm{f}}=0,1\right.$, and 2 cycles), CBR test was carried out as per Japanese Industrial Standards "Test Method for the California Bearing Ratio (CBR) of Soils in Laboratory (JIS A 1211: 2009)". It is noted that since the freeze-thaw method in this study is very time-consuming as compared with the other test standard like ASTM D6035, the above-mentioned freeze-thaw history similar to ASTM D5918 was selected as a fundamental study for examining the effect of freeze-thaw.

\section{Long-term Field Measurement and In-situ Tests at Test Pavement in Cold Regions}

\section{Field Test Site and Field Measurement}

Long-term field measurements of ground temperature (by Platinum resistance thermometer sensor), soil water content (by $\mathrm{ECH}_{2} \mathrm{O}$ probe) and settlement by layer inside the pavement structure (by Strain gage-type displacement transducer) were conducted at a test pavement (4 m width $\times 14 \mathrm{~m}$ length) constructed in Hokkaido, Japan in order to examine the relationship between seasonal 
changes in the freeze/ thaw status or in the water content of pavement structure, and the deformation of each layer. The test pavement shown in Figure 5 is one of typical pavement structures in Hokkaido, in which the top layer of the subgrade is replaced with an anti-frost layer that suppresses frost heave. Figure 5 also shows the arrangement of the measuring instruments. It is noted that the subbase course layer of the test pavement was constituted of the same C-40 as that used in the MR tests, while the anti-frost layer was constituted of coarser crusher-run (C-80), which grading ranged from $80 \mathrm{~mm}$ to $0075 \mathrm{~mm}$ as shown in Figure 2 though the materials were the same.

\section{FWD Tests and Back Analysis}

To understand the temporal changes in the bearing capacity of the pavement structure during the thawing season, FWD tests were conducted in conformance with ASTM D4695 (2008) at the same position of the test pavement 20 times in each year from December through March in 2008 and 2009. It is noted that the freezing index in $2008\left(F=346.0^{\circ} \mathrm{C} \cdot\right.$ days $)$ was approximately $60 \%$ of the 10 -year average freezing index $\left(F=582.7^{\circ} \mathrm{C}\right.$-days in 1997-2007), while the freezing index in $2009(F=$ $502 .{ }^{\circ} \mathrm{C} \cdot$ days) was a little under the average value, indicating that the average temperature in the winter of 2008 is higher than that of 2009. Here, the freezing index $(F)$ is defined as the number of cumulative degree-days during freezing season. FWD tests were performed by using a total of 6 deflection sensors from the deflection sensor $\left(D_{0}\right)$ directly under the loading plate to the farthest deflection sensor $\left(D_{150}\right)$ at the positions of $0,0.2,0.3,0.6,0.9$ and $1.5 \mathrm{~m}$. The measured surface-deflection data from the FWD tests was corrected for the value under load of $49 \mathrm{kN}$ and temperature of $20^{\circ} \mathrm{C}$. Based on the results of FWD tests, the elastic modulus for each layer of the pavement were estimated with the static back-analysis program BALM (Back Analysis for Layer Moduli, Matsui et al. 1998). In the back-analysis, we assume that the test pavement in Figure 5 had a three-layer structure (As layer, base layer, and subgrade layer), in which the subbase course and the anti-frost layer are considered a single layer.
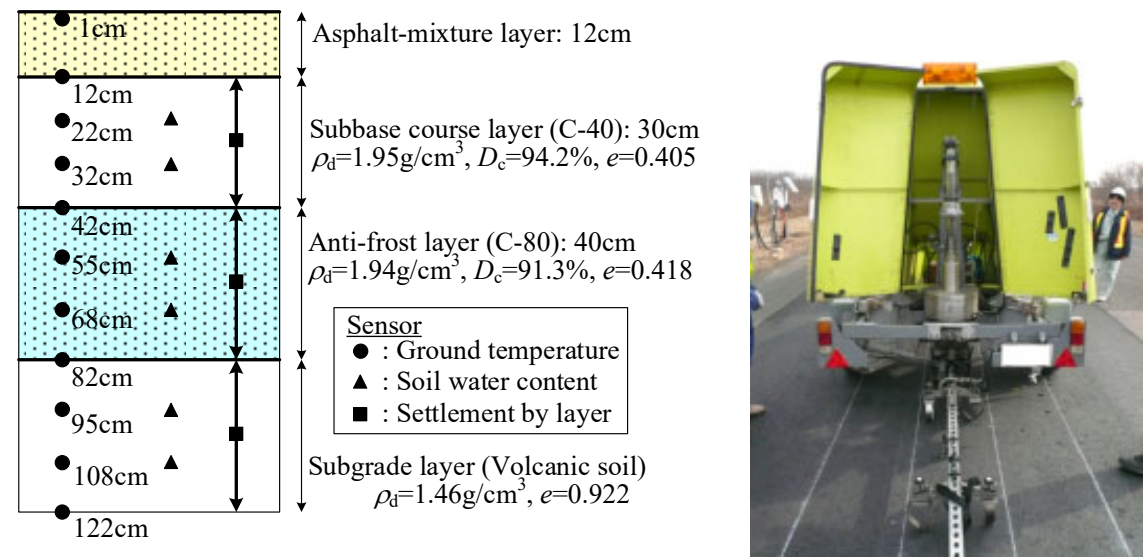

Figure 5. Test pavement for field measurement and FWD test.

\section{RESULTS AND DISCUSSIONS}

\section{Long-term Field Measurement and In-situ Tests}

\section{Long-term Field Measurement}

Figure 6 shows the temporal transitions in daily mean air temperature, frost-penetration depth, daily precipitation, and degree of saturation in each layer of the pavement during the long-term field measurement. According to Figure 6a, the average daily temperature remains below $0{ }^{\circ} \mathrm{C}$ during roughly 3 months from mid-December to early March in both years, and the frost-penetration depth decreased dramatically as the temperature rises starting in mid-March. The frost-penetration depth 
reached only the center of subbase course in 2009 due to smaller freezing index, while it reached the anti-frost layer in 2010. Regarding the changes in water content of subbase course (Figure 6b), there is a tendency for the apparent degree of saturation to decrease rapidly after late December in 2009, when the frost-penetration depth increased dramatically. This is due to functional features of the soil moisture sensor used in the measurement. It was, however, higher after thawing than before freezing. This tendency is also observed in 2008. Therefore, the water content of subbase course tends to be almost constant, except the rapid decrease during the freezing period and the temporary increase during the thawing period and after rainfall.
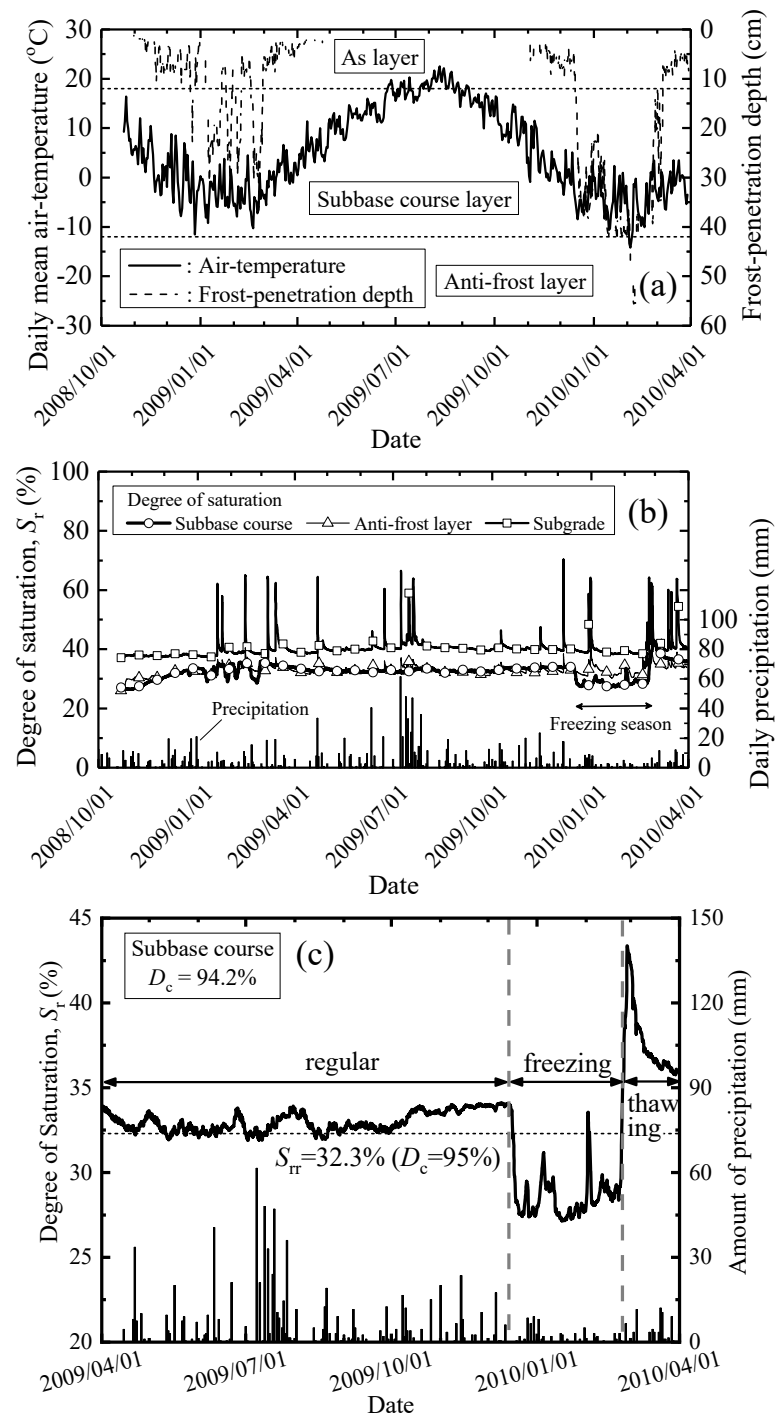

Figure 6. Results of long-term field measurement, (a) air temperature \& frost-penetration depth, (b) daily precipitation \& degree of saturation, and (c) degree of saturation of subbase course).

Figure $6 \mathrm{c}$ shows the daily change in water content measured at the subbase course of the test pavement, together with the daily amount of precipitation. It is evident that the degree of saturation $\left(S_{r}\right)$ during the regular season, except for the freezing period and the thawing period, was nearly stable at around $33 \%$, and that it temporarily increases from the level before freezing to the peak of approximately $43 \%$ during the thawing period. Compared to Figure 3, the $S_{r}$ at the actual subbase course during the regular season nearly conformed to the residual degree of saturation $\left(S_{\text {rr }}\right)$, and it was considerably lower than the degree of saturation $\left(S_{r}\right)$ of $56 \%$ that corresponded to the optimal water content. It is thought, therefore, that the water content of the subbase course during the regular 
season is close to the residual volumetric water content in the actual pavement structure. It is also assumed that the changes in water content, observed from the regular season to the thawing season, seriously influence the mechanical behavior of granular base course materials. This is because it corresponds to the transitional area from the pendular saturation to the fuzzy saturation (Kohgo et al. 1993), where matric suction dramatically fluctuates against changes in the volumetric water content. Based on the above discussion, the degree of saturation for the unsaturated specimen of $36.7 \%$ was set up close to the value during regular season.

\section{FWD Tests}

The temporal transitions in the elastic modulus, $E_{1}, E_{2}$, and $E_{3}$, for the As layer, base layer, and subgrade layer, respectively, are shown in Figure 7 These elastic moduli were determined from the back analysis of FWD test results. No large changes in elastic modulus are observed at any layer in 2008 because the average temperature in the winter of this year was much higher than the 10-year average temperature as mentioned before. On the other hand, in 2009, the elastic moduli of all layers increased as the temperature dropped, and then decreased rapidly from late February (approximately 90 days later) when the temperature began to rise to reach the same level as that in 2008. This indicates that the bearing capacity of the granular base clearly increases with decreasing temperature in the winter, and that it then degrades dramatically during the thawing season. Furthermore, the dependency of elastic modulus on the ground temperature and the soil water content is discussed. Figure 8 plots the relationships between the elastic moduli of base layer $\left(E_{2}\right)$ and the average ground temperature $\left(T_{\mathrm{g}}\right)$ (Figure 8a), and the average degree of saturation $\left(S_{r}\right)$ (Figure $8 \mathrm{~b}$ ), obtained from long-term field measurements during the FWD tests. A clear temperature dependency is observed for the elastic modulus of base layer $\left(E_{2}\right)$, which increases as the average ground temperature decreases after dropping to $0{ }^{\circ} \mathrm{C}$ or below. This is the increased stiffness caused by the freezing of subbase course. Besides, $E_{2}$ decreases slightly with the increment of the degree of saturation when the base is not frozen. Therefore, there is a close relationship between the freeze-thaw action and the seasonal fluctuation in soil water content, and the change in the stiffness of granular base. For example, it is expected that $E_{2}$ will increase during the freezing period and decrease during the thawing period to a value even lower than that before freezing, mainly due to the increase in soil water content at the actual pavement structure as shown in Figure 6c.

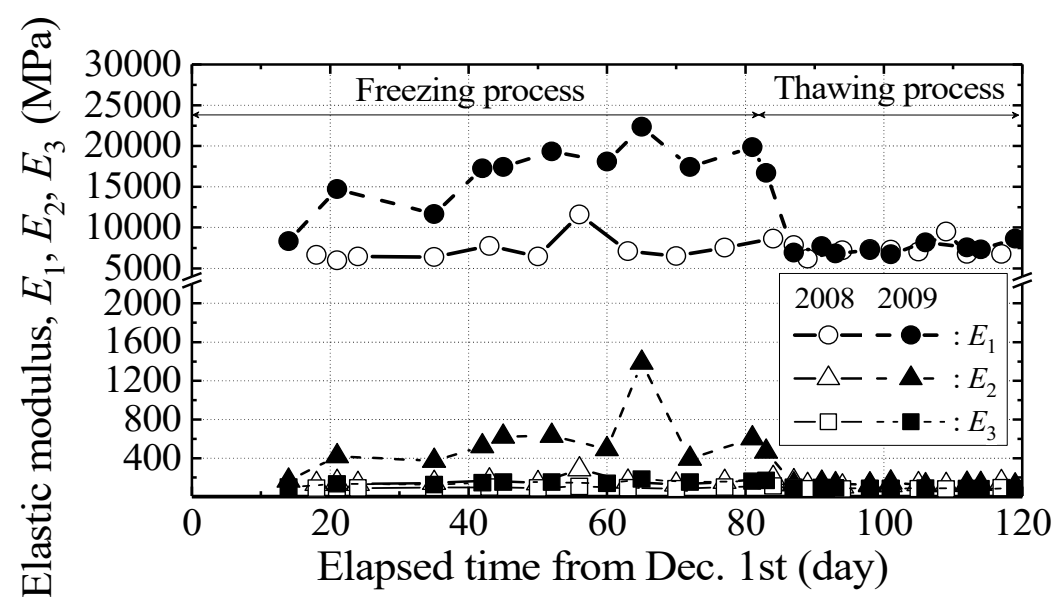

Figure 7. Temporal transitions in the elastic moduli. 

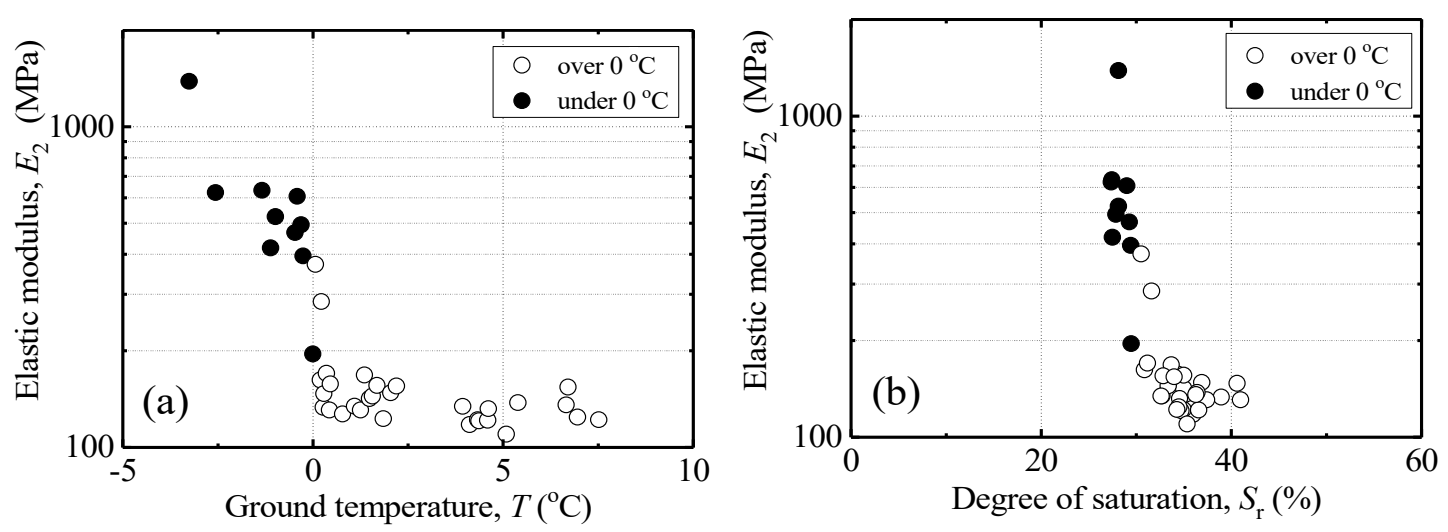

Figure 8. Effects of temperature and water content on elastic modulus of base layer, (a) $E_{2}-T_{\mathrm{g}}$ relations, and (b) $E_{2}-S_{\mathrm{r}}$ relations.

\section{Deformation-Strength Characteristics for Unsaturated Subbase Course Materials}

\section{Effects of Water Content}

Figure 9 shows typical relationships between deviator stress $(q)$ and axial strain $\left(\varepsilon_{a}\right)$ in the last five cycles of loading stage MR-15 (Table 2) for C-40 with different water contents. Regardless of the water content, there was a tendency for elastic deformation with little residual axial strain to be distinguished, and there were few changes in the shape and slope of the hysteresis loop drawn by the loading and unloading of deviator stress during 1 loading cycle. Besides, the shape and slope of the hysteresis loop varied depending on the water content of the specimen, with a tendency for the stiffness to increase and the deformation behavior to become more elastic with the decrease in water content. This indicates that change in the water content strongly influences the resilient deformation characteristics of granular base course materials. These tendency qualitatively matches the results of existing MR tests (e.g. Coronado et al. 2005, Ekblad, J. and Isacsson 2008, Craciun and Lo 2012, Yaghoubi et al. 2016). Consequently, it is concluded that the medium-size triaxial apparatus for unsaturated soils is very applicable to the evaluation of the resilient deformation characteristics of granular base course materials.

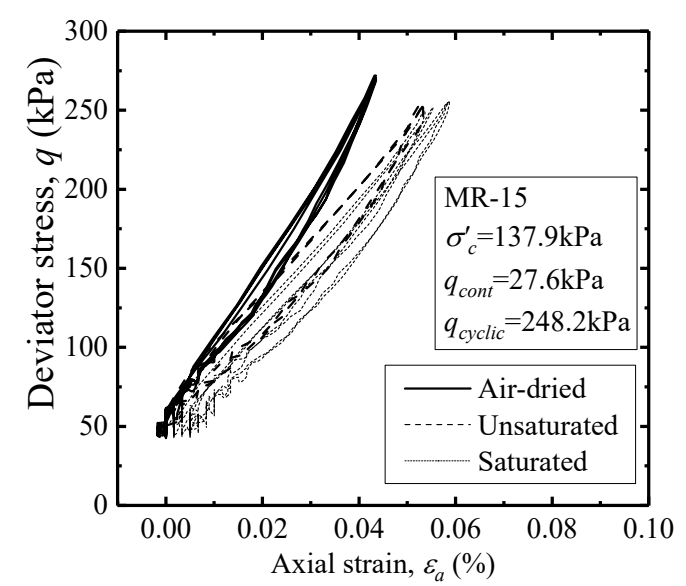

Figure 9. Comparison of hysteresis-loops in MR tests under different water contents.

To quantitatively examine the effect of the water content on the resilient modulus $\left(M_{r}\right)$ for subbase course material, the relationships between the resilient modulus and the deviator stress $(q)$ or the effective mean principal stress $\left(p^{\prime}\right)$ obtained from MR tests of C-40 under various water 
contents and effective confining pressures $\left(\sigma_{c}^{\prime}\right)$ of $20.7 \mathrm{kPa}$ and $34.5 \mathrm{kPa}$ are shown in Figure 10. It is noted that the effective confining pressure for air-dried and saturated conditions is replaced by the net normal stress $\left(\sigma_{n e t}\right)$ for unsaturated condition. When $\sigma_{c}^{\prime}$ is constant, the resilient modulus decreases as the $p^{\prime}$ and the $q$ increases, regardless of the water content, while the resilient modulus increases as the $\sigma_{c}^{\prime}$ increases, regardless of the water content, when the $p^{\prime}$ and the $q$ are constant. The $\sigma^{\prime}{ }_{c}$ is especially predominant against the resilient deformation characteristics of C-40 in case of the same water content. On the other hand, for the plot with the same $p^{\prime}$ and $q$ under a constant $\sigma_{c}^{\prime}$, resilient modulus decreases dramatically as the water content increases, regardless of the $\sigma_{c}^{\prime}$. Therefore, the influences of the water content and stress conditions need to be carefully noted in the development of a simple mathematical model for the resilient deformation characteristics of granular base course materials.

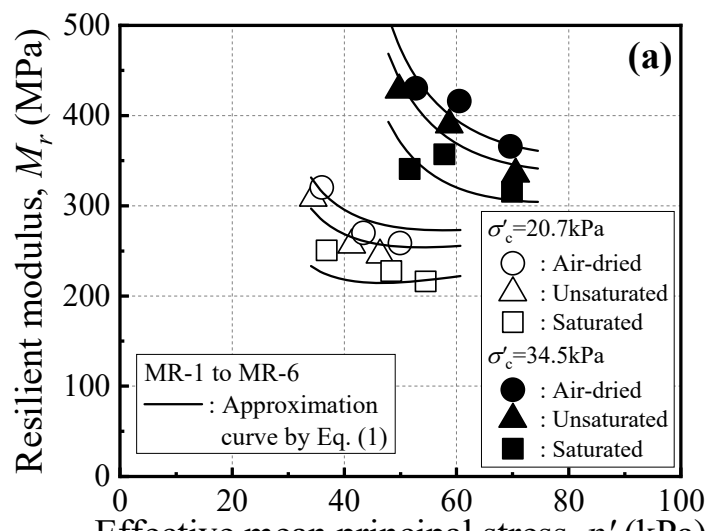

Effective mean principal stress, $p^{\prime}(\mathrm{kPa})$

(a) Effect of effective mean principal stress.

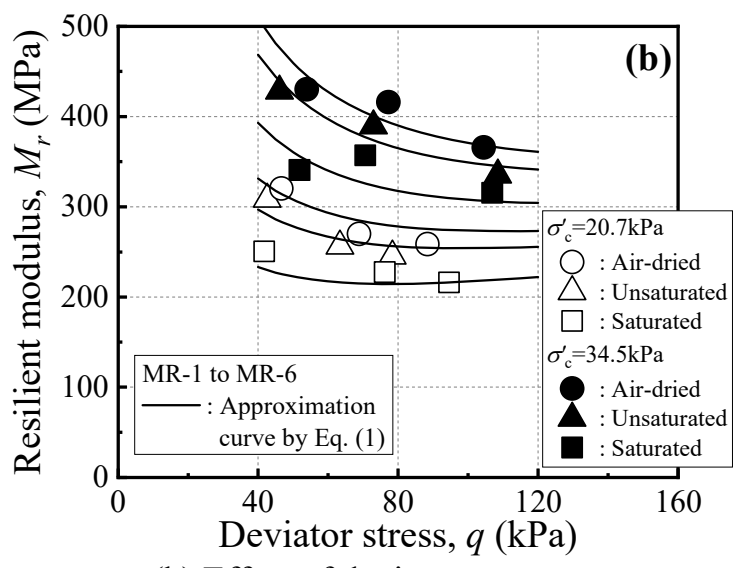

(b) Effect of deviator stress.

Figure 10. Comparison of resilient modulus under different water contents and loading conditions.

On the other hand, Figure 11 shows the relationships for C-40 between CBR and initial water content under different number of freeze-thaw process cycles. The overall tendency is a decrease in CBR caused by the increase in water content. When the test results are compared with those of specimens without freezing $\left(N_{\mathrm{f}}=0\right.$ cycle $)$ to examine differences due only to water content, CBR is found to decrease to nearly $50 \%$ when the condition changes from air-dried to saturated, indicating that the water content has an extremely large influence on CBR of subbase course materials.

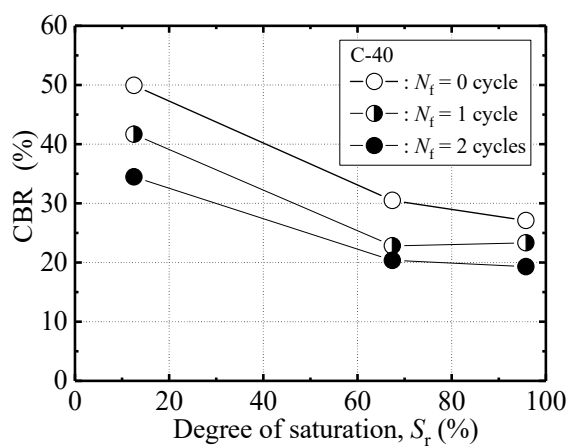

Figure 11. Results of CBR tests under different water contents and freeze-thaw history.

\section{Applicability of Existing Estimation Formula}

So far, various types of mathematical models which can estimate the resilient modulus for granular base course materials in consideration of the stress state at the subbase course layer have been proposed (Uzan 1985, Abe and Saika 1994, Lytton 1995, Yoshida et al. 2003, Yau and Von Quintus 
2002, Yang et al. 2005, Liang et al. 2008, Cary and Zapata 2011, Khoury et al. 2009, Oh et al. 2012, Azam et al. 2013, Ng. et al. 2013, Gu et al. 2015, Han and Vanapalli 2016). This section examines the applicability of Eq. (1) proposed by Liang et al. (2008) to the test results of this study. The equation is like a mathematical model for resilient modulus utilized in the Mechanistic-Empirical Pavement Design Guide (MEPDG, AASHTO 2008).

$$
M_{r}=k_{1} p_{a}\left(\frac{\sigma_{i i}^{\prime}+\chi s}{p_{a}}\right)^{k_{2}}\left(\frac{\tau_{\alpha t}}{p_{a}}+1\right)^{k_{3}}, \quad \chi=\left(\frac{\left(u_{a}-u_{w}\right)_{b}}{s}\right)^{0.55}
$$

where, $k_{1}, k_{2}$, and $k_{3}$ are constants; $\sigma^{\prime}{ }_{i i}$ is bulk stress (effective principle stress sum); $p_{a}$ is atmospheric pressure (normalizing stress, $p_{a}=101 \mathrm{kPa}$ ); $\chi$ is Bishop's effective stress parameter; $s$ is matric suction; and $\tau_{o c t}$ is octahedral shear stress (deviator stress under axisymmetric stress condition); $\left(u_{a}-u_{w}\right)_{b}$ is AEV. Table 3 and Figure 10 show the results of a regression analysis using Eq. (1). The figure indicates that Eq. (1) effectively represents the stress-dependency of resilient modulus in this study in both qualitative and quantitative manners, regardless of the water content.

Table 3. Results of regression analysis using Eq. (1) for $M_{r}$.

\begin{tabular}{lcccc}
\hline Model & $k_{1}$ & $k_{2}$ & $k_{3}$ & $\mathrm{R}^{2}$ \\
\hline Liang et al. (2008) & 4.861 & 1.525 & -2.092 & 0.950 \\
\hline
\end{tabular}

In the above-mentioned CBR tests and triaxial compression tests with monotonic loading (Zhang et al. 2014) on the same C-40, the decrease in CBR and peak strength caused by the increase in the water content have been revealed. Figure 12 compares the resilient modulus $\left(M_{r(C B R)}\right)$ calculated from the CBR value using the empirical formula shown in Eq. (2) utilized in the AASHTO design standard, with the resilient modulus $\left(M_{r(M R)}\right)$ estimated from the regression results of Eq. (1) shown in Figure 10 under various water contents. It is noted that $M_{r(M R)}$ are estimated by assuming the stress state under a $49-\mathrm{kN}$ wheel load, calculated using multi-layer elastic analysis, at an actual Japanese pavement structure.

$$
M_{r}=17.6 \cdot C B R^{0.64} \quad(\text { Yau and Von Quintus 2002) }
$$

Besides, Figure 12 also shows the relationship between the elastic modulus $\left(E_{2}\right)$ for the base layer estimated from the above-mentioned static back-analysis of the FWD test results, and the volumetric water content $(\theta)$ for the subbase course layer measured when conducting the FWD test.

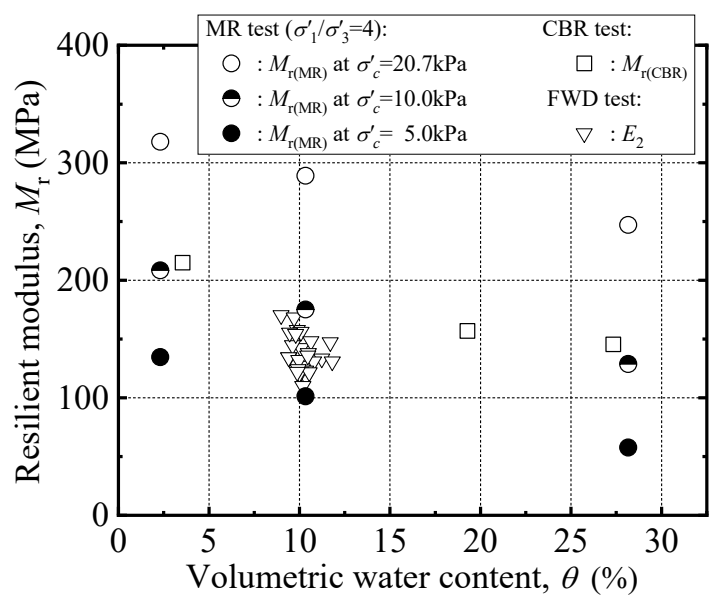

Figure 12. Influence of water content on resilient modulus.

In Figure 12, the decreasing tendencies of all types of resilient moduli with increasing water 
content are in fair agreement with each other, irrespective of the calculation method. While $M_{r(M R)}$ strongly depends on the effective confining pressure $\left(\sigma_{c}^{\prime}\right)$ in case of the same water content, $M_{r(M R)}$ estimated at $\sigma_{c}^{\prime}=11 \mathrm{kPa}$, which is close to the overburden pressure at the actual pavement structure, is nearly equal to the upper limit for $E_{2}$ measured in the test pavement. Furthermore, $M_{r(C B R)}$ is an acceptable qualitative match for $M_{r(M R)}$ when the principal stress ratio $\left(\sigma^{\prime}{ }_{l} / \sigma_{3}{ }_{3}\right)$ is 4 under $\sigma_{c}^{\prime}=11$ $\mathrm{kPa}$, irrespective of $\theta$. Therefore, it seems reasonable to conclude that the suction-control MR test in this study is very quantitatively compatible with the conventionally used CBR and FWD tests in the evaluation of the resilient deformation characteristics of granular base course materials. In addition, it is surmised that Eqs. (1) and (2) adopted in the AASHTO design standard has high applicability in the estimation of the resilient modulus for subbase course in Japanese pavement structures.

\section{Effects of Freeze-Thaw on Resilient Modulus of Unsaturated Subbase Course Materials}

\section{Effects of Freeze-Thaw Action}

The frost heave rate $\left(U_{\mathrm{h}}\right)$, which is a criterion for judging the frost susceptibility of geomaterials in Japan, was $U_{\mathrm{h}}=0.1 \mathrm{~mm} / \mathrm{h}$ or lower for all test conditions, and as the result the frost-susceptibility of the specimens is considered to be low regardless of the freeze-thaw history and the soil water content. On the other hand, a drop in CBR accompanied by an increase in the number of freeze-thaw process cycles is observed in Figure 11, regardless of the water content. In particular, the ratio of decreasing CBR tends to become larger with the decrease in the water content. In Figure 6c, the degree of saturation at the subbase course in an actual pavement structure is lower than that of the specimen in wet condition, except during the thawing season. Thus, it is expected that the effects of the freeze-thaw action on the bearing-capacity characteristics of granular base course materials will be large. These indicate that it is important to give a special consideration to the degradation in the bearing capacity caused by cyclic freeze-thaw actions even in non-frost susceptible granular base, in addition to the effects of an increase in water content during the thawing season, in order to develop the design method for the pavement in cold regions closer to the actual phenomena.

To examine the change in the resilient deformation characteristics of granular base course materials subjected to cyclic freeze-thaw actions, Figure 13 shows the relationships between $M_{r(C B R) \text {, }}$ which were calculated from the results of freeze-thaw CBR tests using Eq. (2), and initial volumetric water content $(\theta)$ under different numbers of freeze-thaw process cycles $\left(N_{f}\right)$. The range from residual volumetric water content $\left(\theta_{r}\right)$ to the optimum volumetric water content $\left(\theta_{\text {opt }}\right)$, which correspond to residual degree of saturation and optimum water content obtained from water retentivity test and compaction test on C-40, was also indicated. When comparing the test results for unfrozen specimens $\left(N_{f}=0\right)$ to examine the effects of only the initial water content on the resilient deformation characteristics, $M_{r(C B R)}$ is found to decrease to nearly $70 \%$ when the condition changes from air-dried to saturated, indicating that the increase in the water content causes the remarkable decrement of the resilient modulus. 


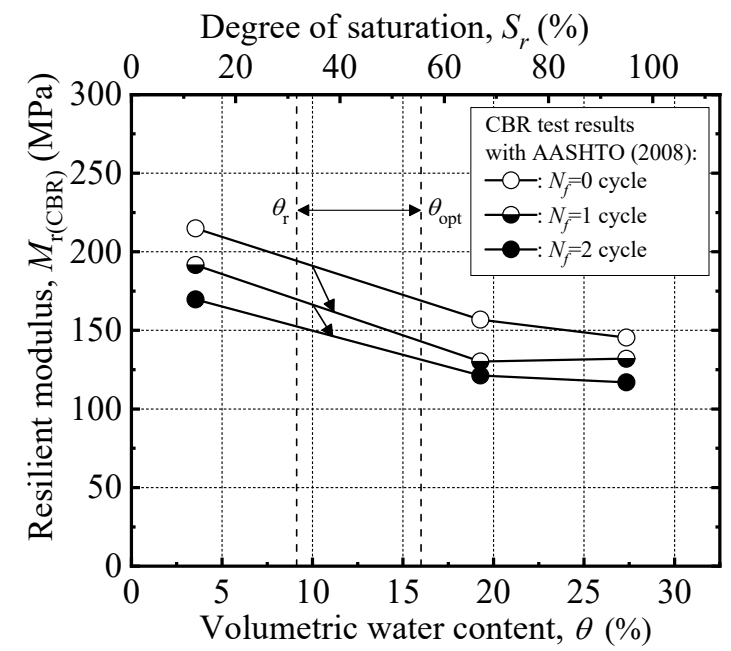

Figure 13. Resilient modulus estimated from freeze-thaw CBR test results.

Furthermore, according to the long-term field measurement at the test pavement, the volumetric water content in the subbase course increases to about 12 13\% during thawing season, although it is kept at almost constant value of around $10 \%$ during regular season except thawing season and freezing season. When being focused on this seasonal fluctuation in water content, it can be found that a decrease in $M_{r(C B R)}$ due to the increase in the number of freeze-thaw process cycles is severe as compared with a decrease in $M_{r(C B R)}$ due to the increase in water content. Besides, according to the long-term field measurement, it is expected that the resilient modulus of subbase course at the actual pavement structures may deteriorate along the arrows shown in Figure 13 when it is exposed to repeated freeze-thaw and the concurrent seasonal fluctuations in water content. Therefore, the freeze-thaw action is considered not only to have a strong influence on the resilient deformation characteristics of granular base course materials but also, as a consequence, to affect the fatigue life of pavement structures in cold regions.

\section{Proposal of Estimation Formula Considering Freeze-thaw Effects}

This section proposes a simple estimation formula that can be used to evaluate the resilient deformation characteristics of granular base course materials with different water contents subjected to repeated freeze-thaw actions, based on Eq. (1), and the applicability is verified. For this purpose, this study assumes the effect of cyclic freeze-thaw actions to be expressed by a compensation function $f\left(N_{f}, \theta\right)$, which uses number of freeze-thaw process cycles $\left(N_{f}\right)$ and volumetric water content $(\theta)$ for the sample as explanatory variables based on the discussions in previous sections. This study also supposed that the resilient modulus $\left(M_{r}\right)$ for granular base course materials subjected to repeated freeze-thaw actions could be estimated using the constitutive equation shown below, which was Eq. (1) multiplied by the compensation function $f\left(N_{f}, \theta\right)$.

$$
M_{r}=f\left(N_{f}, \theta\right) \cdot k_{1} p_{a}\left(\frac{\sigma_{i i}^{\prime}+\chi s}{p_{a}}\right)^{k_{2}}\left(\frac{\tau_{\alpha t}}{p_{a}}+1\right)^{k_{3}}
$$

Figure 14 compares the ratios of $M_{r(C B R)}$ for a freeze-thawed specimen at a given $N_{f}$ against $M_{r(C B R)}$ for an unfrozen specimen at $N_{f}=0$, which is defined as "ratio of resilient modulus $\left(R_{M R}\right)$ ", under various water contents to quantitatively analyze the effect of the water content and freeze-thaw history on the compensation function $f\left(N_{f}, \theta\right)$. The effect of the water content on $R_{M R}$ cannot be clearly discerned irrespective of $N_{f}$, though $R_{M R}$ gradually decreases to a value lower than 1 with the increase in $N_{f}$, regardless of the water content. Therefore, it seems reasonable to conclude that the effects of $\theta$ on the compensation function $f\left(N_{f}, \theta\right)$ was negligible enough, and that the average value of $R_{M R}$ should be adopted as the value of $f\left(N_{f}, \theta\right)$ for each $N_{f}$. 


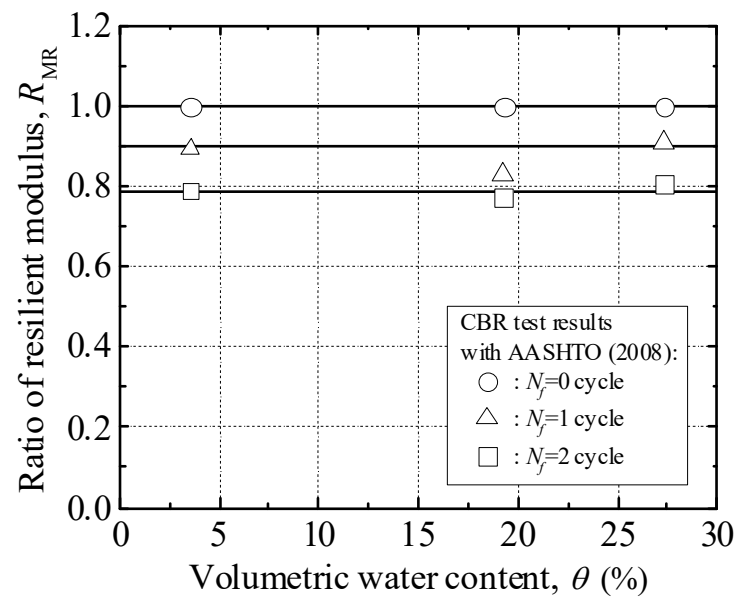

Figure 14. Influence of water content on ratio of resilient modulus.

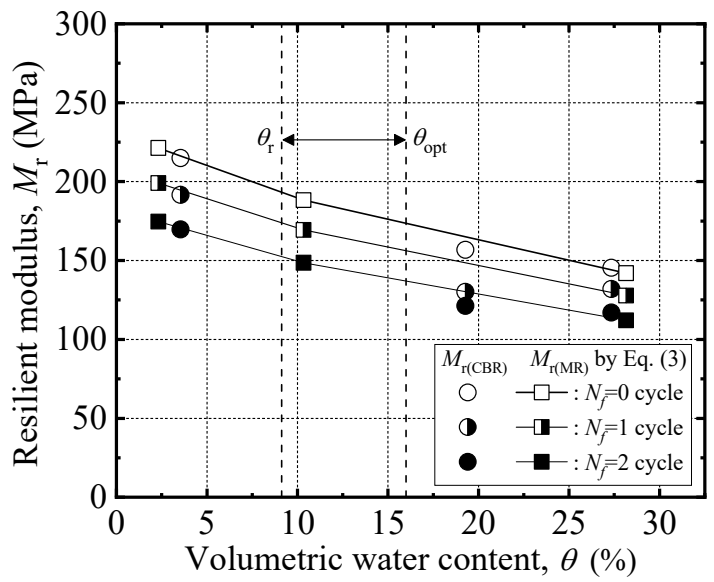

Figure 15. Resilient modulus estimated by newly proposed simple estimation formula.

Figure 15 compares $M_{r(C B R)}$ with the resilient modulus estimated by Eq. (3), which was obtained by multiplying the value of $f\left(N_{f}, \theta\right)$ shown in Figure 14 by $M_{r(M R)}$ when the principal stress ratio $\left(\sigma^{\prime}{ }_{l} / \sigma_{3}{ }_{3}\right)$ is equal to 4 under $\sigma_{c}^{\prime}=11 \mathrm{kPa}$. It is noted that this stress conditions was selected so that $M_{r(M R)}$ approximately coincides with $M_{r(C B R)}$ for unfrozen specimens with the same water content. Although the resilient modulus $\left(M_{r}\right)$ estimated by Eq. (3) is a little lower than $M_{r(C B R)}$ when the volumetric water content was high, Eq. (3) seems to reproduce the overall tendency for the resilient modulus to decrease in concurrence with the increase in the water content and the number of freeze-thaw process cycles. Therefore, it seems reasonable to conclude that Eq. (3), which was newly proposed in this study, is sufficiently applicable to the quantitative evaluation of the resilient modulus for unsaturated subbase course subjected to repeated freeze-thaw actions at the pavement structures in cold regions, Japan. However, since Eq. (3) is proposed based on test results under a small number of freeze-thaw process cycles $\left(N_{f}\right)$, further investigation on the formulation of the compensation function $f\left(N_{f}, \theta\right)$ by performing freeze-thaw CBR tests with a large number of $N_{f}$ is indispensable to clearly explain the effect of repeated freeze-thaw on the resilient modulus $\left(M_{r}\right)$.

\section{UNDERSTANDING OF PHENOMENON AND ITS APPLICATION TO DESIGN METHOD}

\section{Mechanism of Bearing Capacity Reduction due to Freeze-Thaw}

To examine the mechanism of the reduction in the resilient modulus of C-40 due to freeze-thaw, the 
temporal variation of particle moisture content during freeze-thawing is investigated by conducting freeze-thaw tests for a single particle in saturated and surface-dry condition as follows. Here, "particle water content" is water content absorbed in a single particle with surface-dry condition. Test samples (four samples of $100 \mathrm{~g}$ for each test condition) were prepared by allowing natural crusher-run particles having a particle size of 5 to $10 \mathrm{~mm}$ to absorb water for 24 hours, then free water on the surface of the particles was wiped off to obtain the saturated and surface-dry condition. Two kinds of freeze-thaw tests, namely "closed condition" and "open condition", were conducted. Here, a specimen under "closed condition" where the sample was placed in a sealed container assumes a state without air drying like wet condition and saturation condition of the aforementioned freeze-thaw CBR tests, while a specimen under "open condition" where the sample was put in an open tray assumes a state with air drying like the air-dried condition. Freeze-thaw of the specimen was performed by freezing the container and the tray in a freezer of $-10{ }^{\circ} \mathrm{C}$ for 24 hours and thawing them at room temperature of $20^{\circ} \mathrm{C}$ for 24 hours. For comparison, both specimens under closed and open conditions were also prepared by leaving at room temperature for the same period. The test period was one week, and the weight of the specimens was measured every 24 hours.

Figure 16 compares a change in particle moisture content of specimens with and without freeze-thaw history against elapsed time. The moisture content in the single particle is greatly reduced under open condition as compared with the results under closed condition, regardless of the presence or absence of freeze-thaw history. In contrast, under both open and closed conditions, repeated freeze-thaw actions caused a significantly larger decrease in particle moisture content than did leaving specimens at room temperature. These indicate the possibility of particle moisture being expelled to the particle surfaces due to freezing (Figure 17), as well as due to the humidity difference between particle interior and particle surface. For example, when soil particles are subjected to low temperature, the temperature of the particle surface is low and the internal temperature is relatively high at the initial stage, resulting in a temperature gradient within the particle. In case moisture exists in the particle, moisture moves in the heat flow direction due to the temperature gradient. As time passes, the temperature inside the particle equalizes, causing water movement to stop. When melted from this state, the amount of water near the particle surface increases more than the initial state, and refreezing causes further accumulation of water near the surface as shown in Figure 16. This temperature gradient-induced internal movement of particle moisture is also reported in the frost heave in rock and mortar (Akagawa 2004, Nakamura et al. 2010).

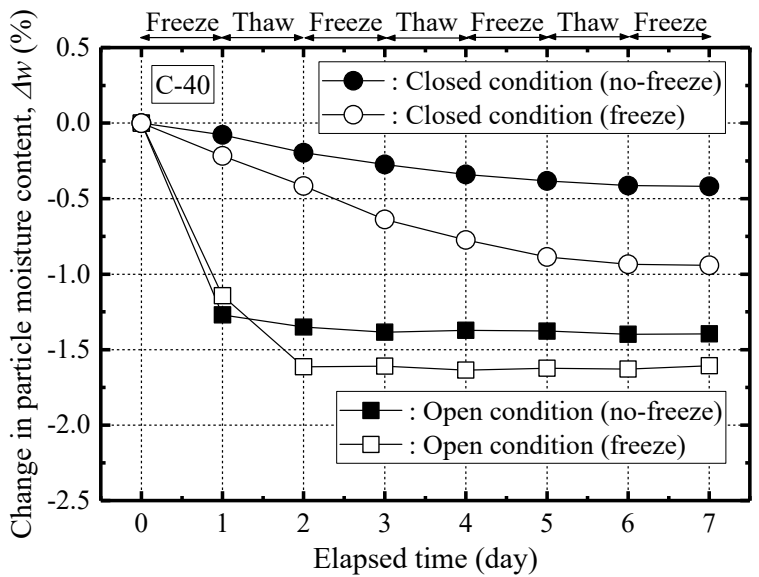

Figure 16. Change in particle moisture content due to freeze-thaw. 


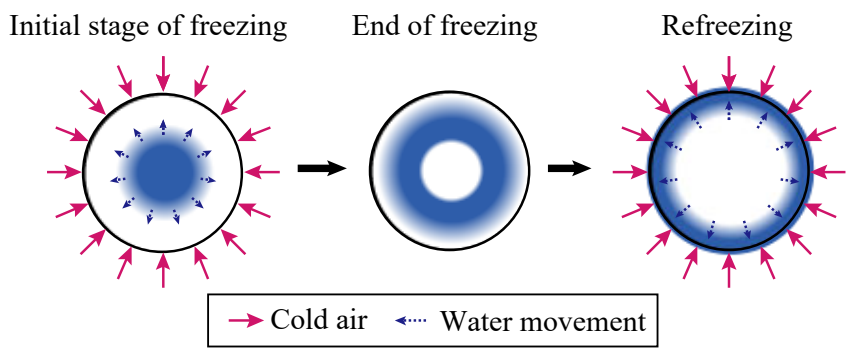

Figure 17. Temperature gradient-induced internal movement of particle moisture.

Considering the discussion in this study, this phenomenon would seriously affect the deformation-strength characteristics of granular base course materials. Figure 18 shows changes in frost heave amount (cumulative displacement from the initial height) during five freeze-thaw process cycles $\left(N_{\mathrm{f}}=5\right)$. The frost heave amount significantly increases with $N_{\mathrm{f}}$ in case of specimens with higher water content, thus likely reducing CBR. The water absorption of C-40 is $3.8 \%$ (Table 1 ), and under wet and saturated conditions, an equivalent amount of particle moisture content would be retained before freezing. Assuming that freezing forces the discharge of particle moisture into voids in a stepwise manner, the increase in frost heave amount with $N_{\mathrm{f}}$, can be explained reasonably. However, as shown in Figure 11, a decrease in CBR due to repeated freeze-thaw is also observed even for air-dried specimens having minimal water content and thus insufficient change to affect the soil structure (Figure 18). Since it seems unlikely that soil structure change due to freeze expansion was a cause for air-dried specimens, there must be other possible factors for the reduction of CBR for air-dried specimens. Figure 19 shows changes in CBR of C-40 with different water contents when the elapsed time from the end of freezing to the CBR test was extended from 0.5 days (normal elapsed time) to a maximum of 7 days. Extending the thawing time for wet and saturated specimens hardly change the CBR though the reduction of CBR due to freeze-thaw can be observed. Meanwhile, the CBR of air-dried specimen increased with longer thawing times, and restored up to $90 \%$ of CBR of unfrozen specimens in case of the seventh day. Furthermore, in case of dry specimens, even if subjected to freeze-thaw action, the change in CBR can hardly be recognized. From these results, it seems reasonable to consider that the reduced CBR of air-dried specimens is due to reduced inter-particle friction resulting from a temporary increase in water content on particle surface caused by freeze-thaw, and that surface water decreases with time, thereby restoring the CBR like Figure 19. Furthermore, a finding that $90 \%$ of the CBR for air-dried specimens was recovered indicates that other factors such as particle breakage due to freeze-thaw have a relatively small effect on the CBR. Meanwhile, since a large amount of water was expelled due to freezing in wet and saturated specimens, this causes irreversible change in the soil structure that prevents the CBR from recovering. Table 4 summarizes the mechanism of bearing capacity reduction due to freeze-thaw. According to Table 4, the decrease in the stiffness by freeze-thawing is due to the deterioration of the soil structure caused by the frost expansion of pore water and/or the reduction in the particle frictional coefficient accompanied by the temperature gradient-induced water movement to the particle surface. The rate of both effects depends on the initial moisture condition, and the stiffness change is reversible in the air-dried condition, while the irreversible change appears in the wet and saturated conditions. Therefore, these indicate that though the resilient modulus estimated by Eq. (3) can evaluate the minimum stiffness immediately after freeze-thaw, there is a possibility that with time passing the reduced stiffness recovers depending on the water content. In the future, it is necessary to confirm the trend of the stiffness recovery process over time, which varies depending on the water content, by performing freeze-thaw CBR tests with a longer thawing time. 


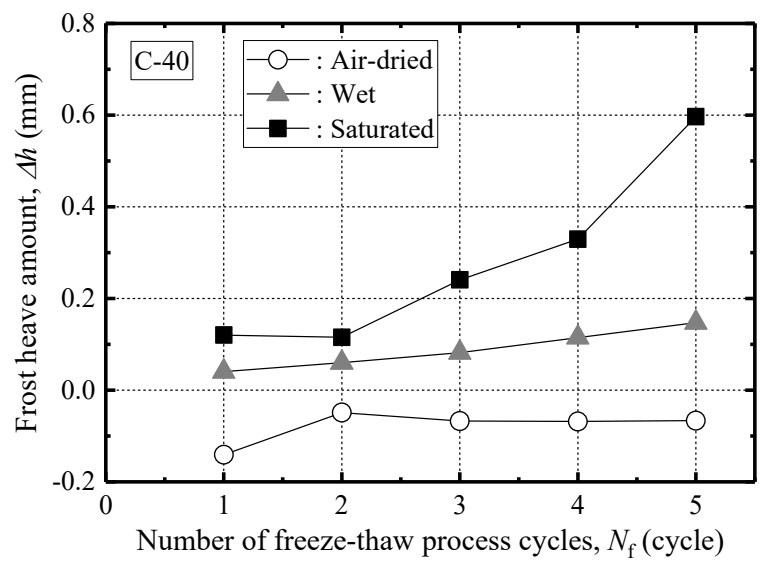

Figure 18. Change in frost heave amount with freeze-thaw process cycles.

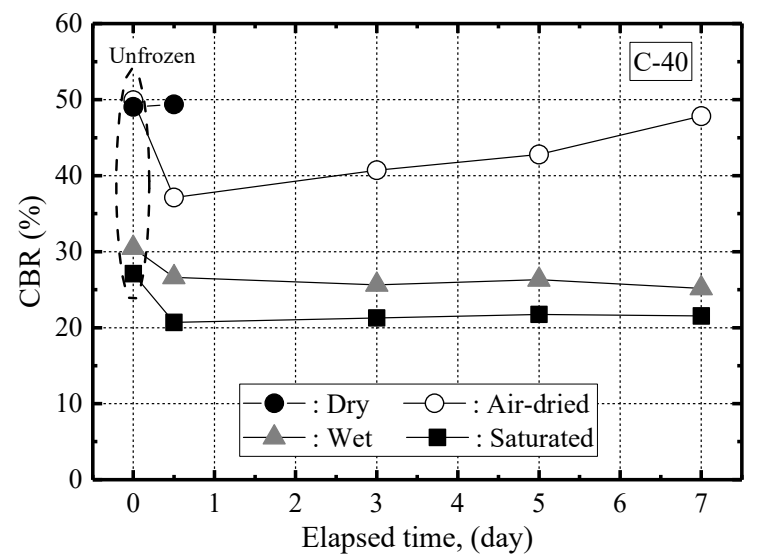

Figure 19. Change in CBR under different elapsed time.

Table 4. Mechanism of bearing capacity reduction due to freeze-thaw.

\begin{tabular}{|c|c|c|c|c|c|}
\hline \multirow{2}{*}{$\begin{array}{l}\text { Water content } \\
\text { conditions }\end{array}$} & \multicolumn{2}{|c|}{ Particle moisture content } & \multicolumn{2}{|c|}{ Soil structure } & Bearing capacity \\
\hline & $\begin{array}{c}\text { Before } \\
\text { freeze-thaw }\end{array}$ & $\begin{array}{c}\text { After } \\
\text { freeze-thaw }\end{array}$ & Image & $\begin{array}{l}\text { Change } \\
\text { amount }\end{array}$ & $\begin{array}{l}\text { Variability } \\
\text { (Factor) }\end{array}$ \\
\hline Dry & & & & None & None \\
\hline Air-dried & & & & None & $\begin{array}{c}\text { Reversible } \\
\text { (Change of friction) }\end{array}$ \\
\hline Wet & & & & Medium & $\begin{array}{c}\text { Irreversible } \\
\text { (Change of structure) }\end{array}$ \\
\hline Saturated & & & & Large & $\begin{array}{c}\text { Irreversible } \\
\text { (Change of structure) }\end{array}$ \\
\hline
\end{tabular}

\section{Effects of Reduced MR due to Freeze-Thaw on Fatigue Life of Pavement}

\section{Fatigue Life Analysis of Pavement}

To evaluate the influences of freezing and thawing on the deterioration in pavement structures, the fatigue life of the asphalt pavement in cold regions is examined by using a theoretical design method for asphalt pavements which considers the changes in the performance of the granular base caused 
by freeze-thaw and the associated seasonal fluctuation in water content. For this purpose, the allowable number of equivalent $49-\mathrm{kN}$ wheel loads $\left(N_{f a}\right)$ against cracking and the allowable number of equivalent $49-\mathrm{kN}$ wheel loads $\left(N_{f s}\right)$ against rutting were calculated by the failure criteria for asphalt pavement given by Eq. (4) and (5) (JRA 2006).

$$
\begin{aligned}
& N_{f a}=\beta_{a 1} \cdot C \cdot\left\{6.167 \times 10^{-5} \cdot \varepsilon_{t}^{-3.291 \cdot \beta_{a 2} \cdot E_{1}^{-0.854+\beta_{a 3}}}\right\} \\
& N_{f s}=\beta_{s 1} \cdot\left\{1.365 \times 10^{-9} \cdot \varepsilon_{a}^{-4.477 \cdot \beta_{s 2}}\right\}
\end{aligned}
$$

where $\beta_{\mathrm{s} 1}, \beta_{\mathrm{s} 2}, \beta_{a 1}, \beta_{a 2}$, and $\beta_{a 3}$ are the compensation rates for AI failure criteria based on the actual situation of Japanese pavement; and $C$ is the material parameter. The tensile strain on the lower surface of the As layer $\left(\varepsilon_{t}\right)$ and the compressive strain on the top layer of the subgrade $\left(\varepsilon_{a}\right)$ under a design wheel load of $49 \mathrm{kN}$ (Figure 20) were calculated using the General Analysis of Multi-layered Elastic Systems (GAMES) program (Maina and Matsui, 2004).

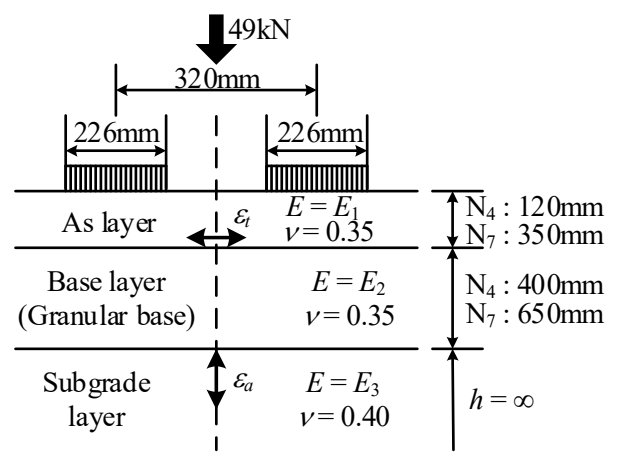

Figure 20. Pavement structure models.

Table 5. Specifications of typical pavement structures in Japan.

\begin{tabular}{cccc}
\hline \multirow{2}{*}{$\begin{array}{c}\text { Roadway } \\
\text { category }\end{array}$} & $\begin{array}{c}\text { Design traffic } \\
\text { volume }\end{array}$ & $\begin{array}{c}\text { As layer } \\
\text { thickness }\end{array}$ & $\begin{array}{c}\text { Base layer } \\
\text { thickness }\end{array}$ \\
\hline $\mathrm{N}_{4}$ & 100 to less thage & $\mathrm{mm}$ & $\mathrm{mm}$ \\
\hline $\mathrm{N}_{7}$ & 3,000 over & 350 & 650 \\
\hline
\end{tabular}

Table 6. Elastic moduli for pavement layers through a year.

\begin{tabular}{lccc}
\hline \multirow{2}{*}{ Name } & $\begin{array}{c}\text { Regular } \\
\text { season }\end{array}$ & $\begin{array}{c}\text { Freezing } \\
\text { season }\end{array}$ & $\begin{array}{c}\text { Thawing } \\
\text { season }\end{array}$ \\
\cline { 2 - 4 } & $\mathrm{MPa}$ & $\mathrm{MPa}$ & $\mathrm{MPa}$ \\
\hline As layer, $E_{1}$ & \multicolumn{3}{c}{$E_{1}=-278.4 M_{\mathrm{p}}+10930$} \\
\hline Base layer, $E_{2}$ & 190.0 & 600.0 & 112.0 \\
\hline Subgrade layer, $E_{3}$ & \multicolumn{3}{c}{90.0} \\
\hline \multicolumn{3}{c}{$M_{\mathrm{p}}:$ Monthly mean temperature of As layer. }
\end{tabular}

This study performed fatigue-life analysis against two typical pavement structures used in Japan (roadway categories of $\mathrm{N}_{4}$ and $\mathrm{N}_{7}$ traffic volumes shown in Table 5) under six different weather conditions in Hokkaido with different freezing indices. Figure 20 and Table 6 show the elastic moduli $(E)$ and the Poisson's ratio $(v)$ for each pavement layer. In general, the Japanese pavement design guide (JRA 2006) assumes the elastic moduli of base and subgrade layers are constant throughout a whole year. However, in this study, to capture the seasonality of the elastic modulus for the base layer $\left(E_{2}\right)$, the $E_{2}$ value varies considering freeze-thaw action and seasonal fluctuation in 
water content. The monthly representative elastic moduli were divided into three types of seasonal $E_{2}$ values $\left(E_{2}\right.$ for freezing season, thawing season, and regular season except freezing and thawing seasons) for the simplicity of the fatigue life analysis. The $E_{2}$ values for thawing season and regular season were estimated by Eq. (3) based on the field-measured data of water content (Figure 6c), the SWCC of C-40, and air temperature data measured through AMeDAS (Automated Meteorological Data Acquisition System). Meanwhile, the $E_{2}$ value for freezing season was set to the average value during the freezing season based on Figure 7. Furthermore, to predict a monthly representative elastic modulus of base layer, this study assumes that when the average frost-penetration depth for the month reaches the base layer, the $E_{2}$ increases due to freezing, and that when the base layer thaws, the $E_{2}$ decreases due to the increase in soil water content. Here, the average frost-penetration depths $(z)$ was calculated by substituting the freezing index obtained from the daily mean air temperatures measured at six AMeDAS observation points located at Hokkaido in 2018 into the modified Berggren formula (Aldrich, 1956) shown below:

$$
z=\alpha \sqrt{\frac{172800 F}{(L / \lambda)_{e f f}}}
$$

where $\alpha$ is a correction coefficient; $F$ is a freezing index which is the average air temperature during frost penetration multiplied by its duration in days; $(L / \lambda)_{\text {eff }}$ is an effective ratio of $L$ to $\lambda, L$ is a latent heat of soil; and $\lambda$ is a thermal conductivity of soil. Besides, a monthly representative elastic modulus of the As layer $\left(E_{1}\right)$ was estimated by referring to the Japanese pavement design manual (JRA 2006) as shown in Table 6, while a monthly representative elastic modulus of the subgrade layer $\left(E_{3}\right)$ was set to the average value during the regular season as a constant value throughout a year based on Figure 7 since this study focuses especially on the influence of the stiffness change of base layer though the $E_{3}$ fluctuates depending on the ground temperature and water content. It is noted that the estimation formula of $E_{1}$ in Table 6 well depicts the results of long-term field measurement and FWD tests in Figure 7. On the other hand, Poisson's ratio $(v)$ was set to 0.35 for As layer and base layer, and to 0.40 for subgrade layer with reference to JRA (2006).

\section{Effects of Freeze-Thaw on Fatigue Life of Pavement}

Figure 21 shows the relationship for $\mathrm{N}_{4}$ and $\mathrm{N}_{7}$ traffic volume pavement structures between the allowable number of wheel loads $\left(N_{f a}\right.$ and $\left.N_{f s}\right)$ and the freezing indexes $(F)$ at the six AMeDAS observation points. This figure compares the fatigue lives with and without considering the climate effects, that is freeze-thaw and water content changing. According to the Japanese pavement design guide (JRA 2006), a lower allowable number of wheel load within $N_{f a}$ and $N_{f s}$ is the threshold for the fatigue life. In Figure 21, for a thin pavement structure ( $\mathrm{N}_{4}$ traffic volume), the cracking failure is critical than the rutting failure, while for a thick pavement structure $\left(\mathrm{N}_{7}\right.$ traffic volume), the trend is reversed. However, both $N_{f a}$ and $N_{f s}$ tend to be longer with the increase in the freezing index. On the other hand, regardless of freezing index and type of pavement structures, both fatigue lives $\left(N_{f a}\right.$ and $N_{f s}$ ) with considering the climatic effects decrease as compared to that without considering the climate effects, under the same analytical conditions. One possible explanation for this is that the drop in the elastic modulus of base layer during thawing season has a stronger influence on the fatigue life than the increase in the elastic modulus of As and base layers during freezing season. Thus it is important to consider the change in the stiffness of base layer caused by freeze-thaw and water content changing when developing a design method with high prediction accuracy for pavement structures in cold regions. 


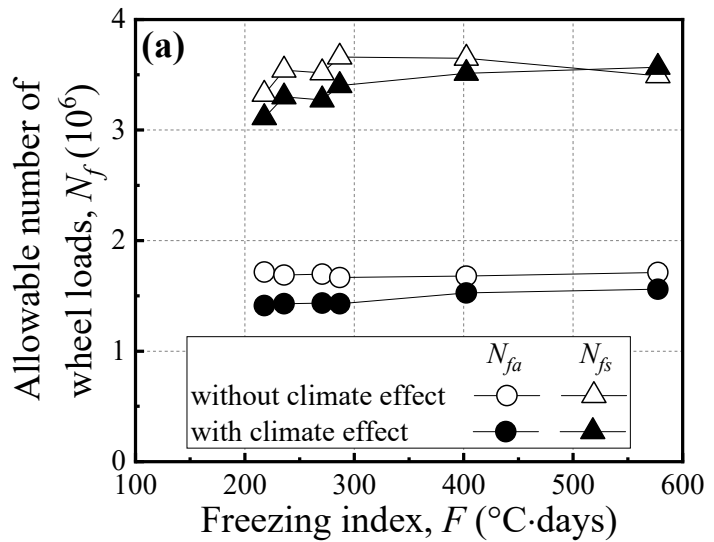

(a) $\mathrm{N}_{4}$ traffic volume pavement structure.

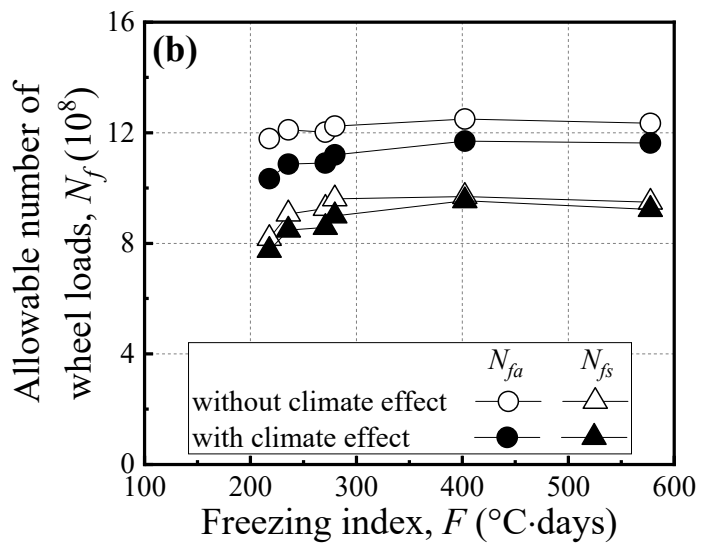

(b) $\mathrm{N}_{7}$ traffic volume pavement structure.

Figure 21. Comparison of fatigue life under different weather conditions.

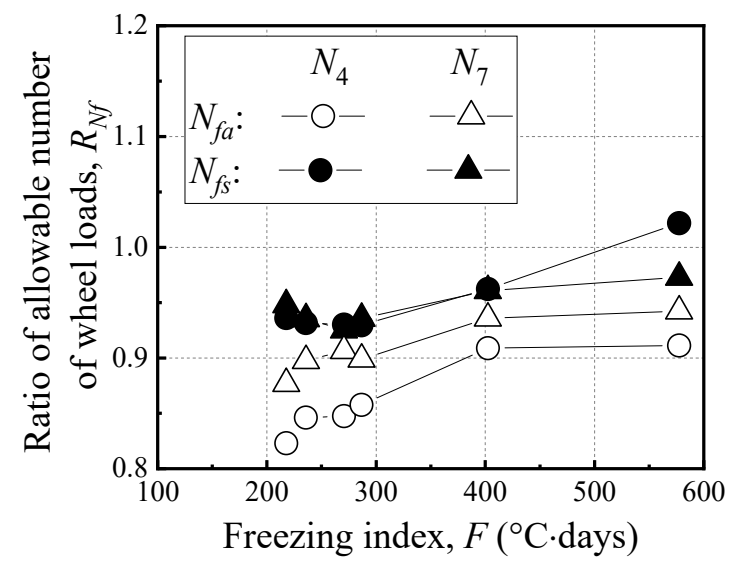

Figure 22. Effects of freeze-thaw on fatigue life of pavement structures.

To clearly discuss the climate effects on the fatigue life of pavement structures, Figure 22 shows the relationships in $\mathrm{N}_{4}$ and $\mathrm{N}_{7}$ traffic volume pavement structures between the ratio of the allowable number of wheel loads $\left(R_{N f}\right)$ and the freezing indexes $(F)$ at the six AMeDAS observation points. The $R_{N f}$ was determined by dividing the allowable number of equivalent $49-\mathrm{kN}$ wheel loads $\left(N_{f a}\right.$ or $\left.N_{f s}\right)$ estimated under changing $E_{2}$ values due to the freeze-thaw action and the concurrent seasonal fluctuation in water content by the allowable number estimated under keeping the $E_{2}$ value constant throughout a year without considering the climate effects. The $R_{N f}$ under almost all analytical conditions are less than 1 except the $N_{f s}$ for the $\mathrm{N}_{4}$ traffic volume pavement structure with high freezing index. This implies that the freeze-thaw action commonly deteriorates the performance of pavement structures and induces the decrease in the fatigue life. However, this deterioration tends to get weaken with the increase in the freezing index. A possible reason is that an increase in the freezing period of base layer may extend the fatigue life when the $N_{f a}$ and $N_{f s}$ are calculated in accordance with the Japanese pavement design guide. Another noticeable tendency is that the pavement structure for the $\mathrm{N}_{7}$ traffic volume has a longer $N_{f a}$ and $N_{f s}$ than those for $\mathrm{N}_{4}$ traffic volume at the same freezing index, which indicates that the influence of the freeze-thaw action on the fatigue life against cracking and rutting becomes more clear in case of the pavement structure with a thin As layer. This is because when the As layer is thin, the base layer can freeze more easily, exaggerating the influence of changes in the stiffness of the base layer. Besides, the $N_{f a}$ is more susceptible to freezing and thawing compared to the $N_{f s}$, irrespective of freezing index and type of pavement structures. This implies that the climate effects against base layer is more significant on fatigue failure due to cracking of AS layer. These results suggest that for improving the applicability and validity of the current Japanese design standard, the introduction of the theoretical design method for pavement structures, which can take account of the effects of the freeze-thaw actions and the 
concurrent seasonal variation in water content, is effective in the asphalt pavements for cold regions, especially in the pavement structures with a thin As layer at the low freezing index area.

\section{CONCLUDING REMARKS}

The following findings can be mainly obtained:

- Because the results of MR tests in this study were very compatible with those of conventional CBR tests and FWD tests, it can be concluded that the medium-size triaxial apparatus for unsaturated soils and the suction-controlled MR test developed in this study are highly applicable as an evaluation method for the resilient deformation characteristics of unsaturated subbase course materials.

- The constitutive equation used in the AASHTO design standard can be applied to the quantitative evaluation of the resilient modulus for Japanese subbase course materials. In addition, it may be possible to use this equation as a simple estimation formula for the resilient modulus of unsaturated granular base course materials subjected to repeated freeze-thaw actions by multiplying the compensation function for the evaluation of the freeze-thaw effects.

- The resilient modulus for subbase course materials was greatly dependent on the stress conditions (principal stress sum, deviator stress, etc.), water content, and freeze-thaw history. As a consequence, the freeze-thaw actions and the concurrent seasonal fluctuations in water content deteriorate the resilient deformation characteristics of granular base course materials and affect the fatigue life of pavement structures in cold regions.

- The internal movement of particle moisture toward the particle surface is induced by the temperature gradient during freezing, which introduces the degradation of soil structure caused by frost expansion of pore water and the decrease in matric suction caused by increasing degree of saturation. The degree of these changes varies with water content, and if only inter-particle friction changes like air-dried specimens, the reduced bearing capacity can be restored, while it cannot be restored if the soil structure is significantly altered like wet and saturated specimens.

- Climate-related degradation of granular base may decrease the fatigue life of asphalt pavements in cold regions by up to $80 \%$ compared to the fatigue life estimated without considering the freeze-thaw and water content change of base layer. Accordingly, when developing a design method with high prediction accuracy for the asphalt pavements in cold regions, it is important to consider the change in the stiffness of base layer caused by the climate conditions.

These indicate that when developing a theoretical model for predicting the mechanical behavior of pavement structures in cold regions and evaluating the long-term performance, it is important to give a special consideration to the degradation in the bearing capacity and resilient modulus caused by repeated freeze-thaw actions even in non-frost susceptible granular base, in addition to the effects of an increase in water content during the thawing season. However, the findings in this study were obtained under limited experimental conditions. Thus, further examination of the validity, limitation of application and so forth needs to be conducted in the future in order for the outcomes of this research to be practically applicable.

\section{ACKNOWLEDGMENTS}

The authors gratefully acknowledge the Civil Engineering Research Institute for Cold Region for their research supports and invaluable comments. This research was supported in part by Grant-in-Aid for Scientific Research (B) (20360206), (C) (15K06214), and (A) (16H02360) from Japan Society for the Promotion of Science (JSPS) KA-KENHI.

\section{REFERENCES}

1. AASTHO 2003. Standard Method of Test for Determining the Resilient Modulus of Soils and 
Aggregate Materials (AASTHO Designation $\mathrm{T}$ 307-99), Standard Specifications for Transportation Materials and Methods of Sampling and Testing, T307-1-T-307-41.

2. AASHTO 2008. Mechanistic-Empirical Pavement Design Guide: A Manual of Practice, Washington.

3. Abe, N., Saika, Y. 1994. Resilient modulus of base course materials, Asphalt, 29(6), pp.9-13. (in Japanese)

4. Abe, R., Tako, J., Kubo, Y. 2009. Stain characteristics of asphalt pavements in cold, snowy regions during the midwinter and thawing seasons, Journal of Pavement Engineering, 14, pp.147-154. (in Japanese)

5. Akagawa, S. 2004. Frost heave process of porous materials and its macroscopic ice lens initiation mechanism, Journal of the Japanese Society of Snow and Ice, 66(2), pp.149-161. (in Japanese)

6. Aldrich, H.P. 1956. Frost penetration below highway and air-field pavement, Highway Research Board Bulletin, No.135, pp.124-149.

7. Aoyagi, T., Yang, J., Matsutani, S., Ishikawa, T., Nakamura, T., Momoya, Y. 2019. Development of freeze-thaw water retention test apparatus for coarse granular materials, In Sundaram, Shahu \& Havanagi (eds), Geotechnics for Transportation Infrastructure, Proc. intern. conf., Delhi, 7-8 April 2018, Vol. 2, pp.409-422.

8. ASTM International (ed.) 2008. Standard guide for general pavement deflection measurement (ASTM D4695-03), ASTM International.

9. ASTM International (ed.) 2013. Standard test methods for frost heave and thaw weakening susceptibility of soils (ASTM D5918), ASTM International.

10. ASTM International (ed.) 2013. Standard test method for determining the effect of freeze-thaw on hydraulic conductivity of compacted or intact soil specimens using a flexible wall permeameter (ASTM D6035), ASTM International.

11. Azam, A. M., Cameron, D. A., Rahman, M. M. 2013. Model for prediction of resilient modulus incorporating matric suction for recycled unbound granular materials, Can Geotech J, 50(11), pp.1143-1158.

12. Bozyurt, O., Keene, A. K., Tinjum, J. M., Edil, T. B., Fratta, D. 2013. Freeze-thaw effects on stiffness of unbound recycled road base, Mechanical Properties of Frozen Soils STP1568-EB, pp.3-21.

13. Cary, C. E., Zapata, C. E. 2011. Resilient Modulus for Unsaturated Unbound Materials, Road Materials and Pavement Design, 12(3), pp.615-638.

14. Coronado, O., Fleureau, J., Correia, A., Caicedo, B. 2005. Influence of suction on the properties of two granular road materials, In I. Horvli (ed), The 7th International Conference on the Bearing Capacity of Roads, Railways and Air-fields, Proc. intern. conf., Trondheim, 27-29 June 2005, [1/1(CD-ROM)260].

15. Craciun, O., Lo, S.-C. R. 2012. Matric suction measurement in stress path cyclic triaxial testing of unbound granular base materials, Geotechnical Testing Journal, 33(1), pp.33-44.

16. Edil, T. B., Cetin B. 2015. Freeze-thaw performance of chemically stabilized natural and recycled highway materials, Sciences in Cold and Arid Regions, 7(5), pp.482-491.

17. Ekblad, J., Isacsson, U. 2008. Water in coarse granular materials: Resilient and retentive properties, In Ellis, Yu, McDowell, Dawson \& Thom (eds), Advances in Transportation Geotechnics, Proc. intern. conf., Nottigham, 25-27 August 2008, pp.117-123.

18. Gu, F., Sahin, H., Luo, X., Luo, R., Lytton, R. L. 2015. Estimation of resilient modulus of unbound aggregates using performance-related base course properties, Journal of Materials in Civil Engineering, 27(6), pp.1-10.

19. Han, Z., and Vanapalli, S. K. 2016. State-of-the-Art: Prediction of Resilient Modulus of Unsaturated Subgrade Soils, International Journal of Geomechanics, 16(4), 04015104.

20. Ishikawa, T., Kawabata, S. 2016. Influence of freeze-thaw on mechanical behavior of granular base and fatigue life of pavement structures in Japan, ASCE Geotechnical Special Publication (GSP), 262, ASCE, pp.77-85.

21. Ishikawa, T., Kawabata, S., Kameyama, S., Abe, R., Ono, T. 2012. Effects of freeze-thawing on mechanical behavior of granular base in cold regions, In Miura, Ishikawa, Yoshida, Hisari \& 
Abe (eds), Advances in Transportation Geotechnics II, Proc. intern. conf., Sapporo, 10-12 September 2012, pp.118-124.

22. Ishikawa, T., Zhang, Y., Tokoro, T., Miura, S. 2014. Medium-size triaxial apparatus for unsaturated granular subbase course materials, Soils and Foundations, 54(1), pp.67-80.

23. Japanese Geotechnical Society 2003. Test Method for Frost Susceptibility of Soils (JGS 0172-2003), Standards of Japanese Geotechnical Society for Laboratory Soil Testing Methods, pp.45-50.

24. Japanese Standards Association 2009. Test Method for the California Bearing Ratio (CBR) of Soils in Laboratory (JIS A 1211: 2009), Japanese Industrial Standards. (in Japanese)

25. Japan Road Association (ed.) 2006. Pavement design manual, Japan Road Association. (in Japanese).

26. Japan Road Association (ed.) 2007. Handbook of pavement investigation and examination methods, Japan Road Association. (in Japanese)

27. Jong, D. T., Bosscher, P., Benson, C. 1998. Field assessment of changes in pavement moduli caused by freezing and thawing, Transportation Research Record: Journal of the Transportation Research Board, 1615, pp.41-48.

28. Kato, S., Kawai, K. 2000. Deformation characteristics of a compacted clay in collapse under isotropic and triaxial stress state, Soils and Foundations, 40(5), pp.75-90.

29. Khoury, N. N., Brooks, R., Khoury, C. N. 2009. Environmental influences on the engineering behavior of unsaturated undisturbed subgrade soils: Effect of soil suctions on resilient modulus, Int. J. Geotech. Eng., 3(2), pp.303-311.

30. Kohgo, Y., Nakano, M., Miyazaki, T. 1993. Theoretical aspects of constitutive modelling for unsaturated soils, Soils and Foundations, 33(4), pp.49-63.

31. Kootstra, B. R., Ebrahimi, A., Edil, T. B., Benson, C. H. 2010. Plastic Deformation of Recycled Base Materials, GeoFlorida 2010: Advances in Analysis, Modeling \& Design, pp.2682-2691.

32. Kubo, H. 1979. Countermeasure for frost heaving of asphalt pavements in cold, snowy regions, JSCE Magazine "Civil Engineering”, 64(2), pp.10-16. (in Japanese)

33. Liang, R. Y., Rabab'ah, S., Khasawneh, M. 2008. Predicting Moisture-Dependent Resilient Modulus of Cohesive Soils using Soil Suction Concept, Journal of Transportation Engineering, 134(1), pp.34-40.

34. Lytton, R. L. 1995. Foundations and pavements on unsaturated soils. Keynote Address, Proc. 1st Int. Conf. on Unsaturated Soils, Vol. 3, Balkema, Rotterdam, the Netherlands, pp.1201-1220.

35. Maina, J.W. and Matsui, K. 2004. Developing software for elastic analysis of pavement structure responses to vertical and horizontal surface loadings, Transportation Research Records, No.1896, pp.107-118.

36. Matsui, K., Kurobayashi, I., Nishiyama, T. 1998. Effort for improving accuracy of pavement layer moduli estimated from FWD test data, Journal of Pavement Engineering, 3, pp.39-47. (in Japanese)

37. Mori, T., Kamiya, K., Chiba, T., Uzuoka, R., Kazama, M. 2009. The functional model of the soil-water characteristic curve used the logistic function during cyclic shearing, 44th Japan national conference on geotechnical engineering, Proc. dom. conf., pp.1519-1520. (in Japanese)

38. Nakamura, D., Goto, R., Ito, Y., Yamashita, S., Suzuki, T. 2010. Differences in frost susceptibility of rock and soil, Journal of Japan Society of Civil Engineers C, 66, pp.472-486. (in Japanese)

39. Ng, C. W. W., Zhou, C., Yuan, Q., Xu, J. 2013. Resilient modulus of unsaturated subgrade soil: experimental and theoretical investigations, Can. Geotech. J., 50(50), pp.223-232.

40. Oh, J. H., Fernando, E.G., Holzschuher, C., Horhotab, D. 2012. Comparison of resilient modulus values for Florida flexible mechanistic-empirical pavement design, International Journal of Pavement Engineering, 13(5), pp.472-484.

41. Simonsen, E., Icacsson, U. 1999. Thaw weakening of pavement structures in cold regions, Cold Regions Science and Technology, 29, pp.135-151.

42. Simonsen, E., Janoo, V. C., Icacsson, U. 2002. Resilient properties of unbound road materials 
during seasonal frost conditions, Journal of Cold Regions Engineering, 16(1), pp.28-50.

43. Tatsuoka, S., Shibuya, S. 1992. Deformation characteristics of soils and rocks from field and laboratory tests. In D. Toll (ed), The 9th Asian Regional Conference on Soil Mechanics and Geotechnical Engineering, Proc. intern. conf., Bangkok, 9-13 December 1991, 2, pp.101-170.

44. Uzan, J. 1985. Characterization of granular pavement materials, In: Transportation Research Record 1022, TRB, National Research Council, Washington D.C., pp.25-59.

45. Yaghoubi, E., Disfani, M. M., Arulrajah, A., Kodikara, J. 2016. Impact of Compaction Methods on Resilient Response of Unsaturated Granular Pavement Material, In A. G. Correia (ed), Procedia Engineering Advances in Transportation Geotechnics 3. The 3rd International Conference on Transportation Geotechnics (ICTG 2016), Volume 143, 2016, pp.323-330.

46. Yang, S. R., Huang, W. H., Tai, Y. T. 2005. Variation of Resilient Modulus with Soil Suction for Compacted Subgrade Soils, Transportation Research Record, No. 1913, pp.99-106.

47. Yau, A., Von Quintus, H. L. 2002. Study of LTPP Laboratory resilient modulus test data and response characteristics: Final Report, Publication No. FHWA-RD-02-051, U.S. Dept. of Transportation, Federal Highway Administration, McLean, VA, pp.1-161.

48. Yoshida, N., Sugisako, Y., Nakamura, H., Hirotsu, E. 2003. Resilient modulus of hydraulic mechanically stabilized slag base-course material, In Di Benedetto et al. (eds), Deformation Characteristics of Geomaterials, Proc. intern. conf., Lyon, 22-24 September 2003, pp.293-298.

49. Zaman, M. M., Laguros, J. H., Zhu, J. G. 1999. Durability Effects on Resilient Moduli of Stabilized Aggregate Base, Transportation Research Record, No. 687, pp.29-39.

50. Zhang, Y., Ishikawa, T., Tokoro, T., Nishimura, T. 2014. Influences of degree of saturation and strain rate on deformation-strength characteristics of unsaturated granular subbase course material, Transportation Geotechnics, 1(2), pp.74-89. 